\title{
PROSPECTS FOR ENERGY CONSERVATION \\ IN THE \\ PIPELINE INDUSTRY
}

by

William F. Banks

\author{
Technical Report - Tasks 4 and 5 \\ Contract $\mathrm{EY}-76-\mathrm{C}-03-1171$ \\ Department of Energy \\ San Francisco Operations Office \\ 1333 Broadway \\ Oakland, California 94612
}

\section{November 1977}

P. O. IX 1620, LA JOLLA, CALIFORNIA 92038, TELEPHONE (714) 453-0060 


\section{DISCLAIMER}

This report was prepared as an account of work sponsored by an agency of the United States Government. Neither the United States Government nor any agency Thereof, nor any of their employees, makes any warranty, express or implied, or assumes any legal liability or responsibility for the accuracy, completeness, or usefulness of any information, apparatus, product, or process disclosed, or represents that its use would not infringe privately owned rights. Reference herein to any specific commercial product, process, or service by trade name, trademark, manufacturer, or otherwise does not necessarily constitute or imply its endorsement, recommendation, or favoring by the United States Government or any agency thereof. The views and opinions of authors expressed herein do not necessarily state or reflect those of the United States Government or any agency thereof. 


\section{DISCLAIMER}

Portions of this document may be illegible in electronic image products. Images are produced from the best available original document. 
1.0 INTRODUCTION $\ldots \ldots \ldots \ldots \ldots \ldots \ldots \ldots \ldots \ldots \ldots \ldots \ldots$

1.1 objectives $\ldots \ldots \ldots \ldots \ldots \ldots \ldots \ldots \ldots \ldots \ldots \ldots \ldots$

1.1 .1 Purpose of the Project .......... 1-1

1.1 .2 Purpose of this Report ........... 1-1.

1.2 Method of Approach .................. 1-1

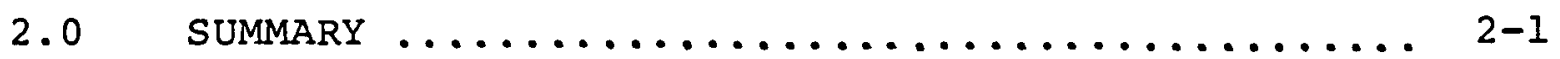

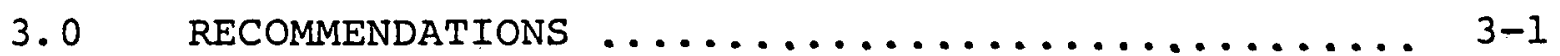

4.0 THE CONVENTIONAL SCENARIO $\ldots \ldots \ldots \ldots \ldots \ldots \ldots . \ldots 4-1$

5.0 UNCONVENTIONAL SCENARIO .............. 5-1

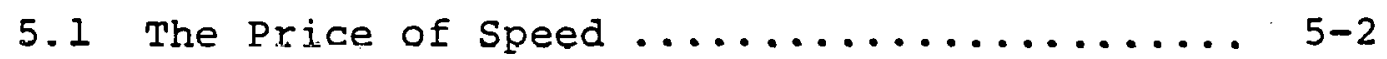

5.2 Characterization of the Modal Mix ....... 5-13

5.3 A Criterion of Merit .............. 5-14

5.4 Optimization of the Modal Mix ......... 5-17

5.5 Modal Economies ................. 5-2l

5.6 Freight-Passenger Information .......... 5-23

5.7 Compatibility with Projected Trends ...... 5-23

6.0 FREIGHT PIPELINES $\ldots \ldots \ldots \ldots \ldots \ldots \ldots \ldots \ldots \ldots \ldots$. 6 .

6.1 History of Freight Pipelines ........... 6-1

6.2 System Development Requirements ......... 6-4

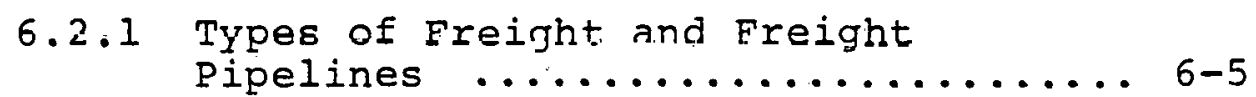

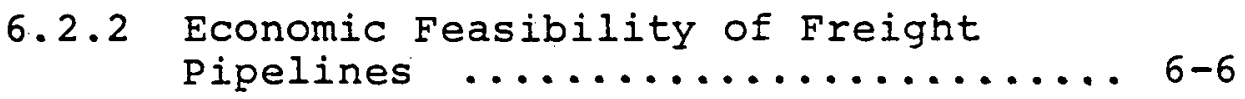

REFERENCES

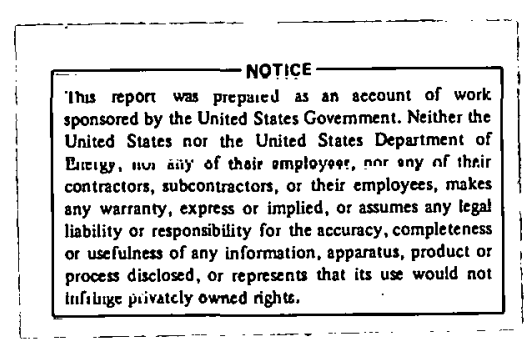

DISTRIDUY'TON OF TEIS DOCUMENT IS UNLIMTTED 


\section{LIST OF FIGURES}

3.0-1 Generic Phase 2 Schedule ............. 3-4

4.0-1 Energy Supply Projection ............. 4-2

4.0-2. Energy Consumption Projection ........... 4-3

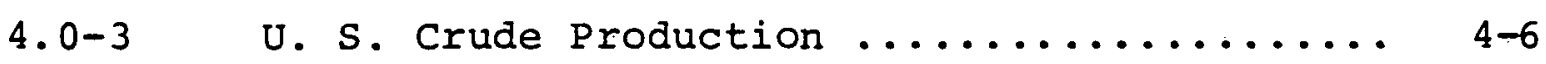

4.0-4 U. S. Petroleum Supply and Demand ........ 4-7

5.1-1 Single-Vehicle Motion Resistance ......... 5-3

5.1-2 Single-Vehicle Specific Power .......... 5-4

5.1-3 Motion Resistance of Convoys ........... 5-5

$5.1-4 \quad$ Specific Power of Convoys ............ 5-6

5.1-5 Specific Powers of Land on Fluid Medium Transport Modes ............... 5-12

5.2-1 Energy Economy of Transportation Modes .... 5-16

5.4-1 Improvement of the Modal Mix ......... 5-18

5. 4-2 Rail Fuel Efficiency vs. Speed [Hopkins 75] ....................... 5-19

5.5-1 Apparent* Dollar Economy of Transportation Modes .......................... 5-23 


\section{LIST OF TABLES}

1.1.1 Project Reports.......................... AGA Projection of Gas Production Under Full Deregulation $(1012 \mathrm{Sch} / \mathrm{hr}) \ldots \ldots \ldots \ldots$.......

5.1-1 Comparison, $\sqrt{\sigma_{\mathrm{u}} / \rho}$ and $\sqrt{\mathrm{E} / \mathrm{p}}, 1950 \ldots \ldots \ldots$ 5-8

5.1-2. Comparison, $\sqrt{\sigma_{\mathrm{U}} / \rho}$ and $\sqrt{\mathrm{E} / \rho}, 1975-77 \ldots \ldots$ 5-9

5.1-3 Power-Law Dependence, Specific Power vs. Speed ....................... 5-11

5.2-1 Estimated Average Parameters for Transport Modes .................. 5-15

5.5-1 Inverse tariffs of transportation modes ... 5-24

6.1-1 Slurry Pipelines in Operation by $1975 \ldots \ldots$ 6-2

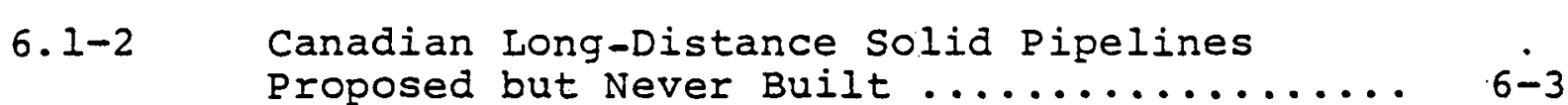




\section{Abstract}

A qualitative projection (the "baseline scenario.") is made of the pipeline industry growth to the year 2000. This projection is based on the conventional wisdom of the industry. It is concluded that, to achieve significant growth, the industry must develop the capability, called freight pipeline, to move other commodities than oil and gas, i.e., bulk and packaged goods. Technical and economic performance criteria are identified which, if met by the freight pipeline capability, could induce modal shifts resulting in a reduction of total transportation energy consumption, and would offer other benefits, including compatibility with high-speed rail passenger service. 


\subsection{INTRODUCTION}

1.1 Objectives

1.1.1 Purpose of the Project

The work reported here is a part of a project which is being conducted by the team of systems, science and Software $\left(S^{3}\right)$ and Pipe Line Technologists, Inc. (Pipetech) of Houston, under DOE contract EY-76-C-03-1171, "Energy Study of Pipeline Transportation Systems." The basic purpose of the project is to assess the susceptibility of the oil, gas, and other pipeline industries to energy-conservative technological innovations, and to identify the necessary research, development, and demonstrations $(R, D, \& D)$ to exploit those opportunities.

The project final report is being published as $s^{3}$ report SSS-R-77-3020, "An Energy Study of Pipeline Transportation Systems." That final report will be a summary, combining the results from the seven task reports listed in Table 1.1-1. As will be noted from the table, this present report is one of those task reports.

\subsubsection{Purpose of this Report}

This report presents the results of Task 4 , an assessment of the future of the industry, and of Task 5, a brief review of the technology of freight pipelines.

\subsection{Method of Approach}

The discussion begins with aiqualitative projection of industry growth based on the conventional wisdom of the industry, and is termed the "baseline scenario." This projection ohows that the pipeline industry, if it follows present trends, will not be a growth industry. To achieve significant growth, the industry must expand into new markets. That is, pipelines must be developed, built, and operated to transport other commodities than oil and gas. Such systems are hereafter referred to as freight pipelines. 
TABLE 1.1-1

Project Reports

SSS-R-77-

3020

$302 \mathrm{I}$

3022

3023

3024

3025

3027

3069
Title

An Energy Study of Pipeline Transportation Systems - Executive Summary

An Economic Model of Pipeline Transportation Systems

Energy Consumption in the Pipeline Industry

Slurry Pipelines - Economic and Political Issues - A Review

Federal Regulation of the Pipeline Industry

Efficiency Improvements in Pipeline Transportation Systems

Prospects for Energy Conservation in the Pipeline Industry

$\mathrm{s}^{3}$ Financial Projection Model - Preliminary User's Manual and System Overview
Associated

Tasks

AII

1

(partial)

1

2.1

2.2

3

4,5

1 (partial) 
Three basic questions then arise, all of which may be phrased in terms of feasibility. Are freight pipelines, on any significant scale,
- economically feasible?
- technically feasible?
- politically feasible?

These questions are addressed in this order because, until the possibility of an affirmative answer to the question of economic feasibility is seen, there is little point in pursuing the others in any depth.

The approach just described is somewhat unconventional. The more customary approach is to postulate a business-as-usual scenario as the baseline, then examine perturbations on that scenario, i.e., to explore the indicated effects of scenarios which embody more or less governmental action than the baseline. The present approach is preferred in this case, however, because it is believed to be both simpler and more realistic.

The conventional wisdom perceives quite well what the government is attempting to accomplish, and reflects a realistic composite assessment of how successful those efforts will be. The only way to outsmart the conventional wisdom is to introduce a totally unconventional factor, as will be done in section 5.0 below. This of course is exactly the proper role for the DoE, i.e., to support the research, development, and demonstration which is necessary to enable the industry to grow in new directions which serve the national interest, but which would be very unlikely without such support. 


\subsection{Summary}

The consensus of industry opinion is that, over the rest of the 21 st century, the amounts of oil and gas produced in the United States will decline, while demand continues to increase. In both cases, some of the shortfall will be offset by imports and a small amount of synthetics, so that the total amount of oil and gas delivered to customers will not decline and will probably increase somewhat.

The consequence of this scenario for the pipeline industry is that total ton-miles of traffic will increase only slightly, but total miles of operating system will continue to increase more strongly because for a while at least, old lines will be retired from service at a slower rate than new lines are brought into service. Later, as fewer new discoveries are made and old sources deplete, retirements will exceed new additions, and the trend will reverse. Thus, for a number of years yet, moderate growth will continue, but at a declining rate of increase. There is no booming expansion in the future of the pipeline industry, unless some completely new applications can be found, i.e., unless ways can be found to move other commodities than oil and gas.

When one reflects on the strong and attractive advantages of pipeline transport, it is easy to become wistful. Pipelines generally are much the cheapest, quietest, least obtrusive, safest, and most rellable mode of freight transport. The compensating offsets are that they are also the slowest, and they can only, within the limits of today's applications, move fluids and a few powdered solids. If a way could be found to enable them to move other commodities and packaged freight, at moderately faster speeds, then the advantages enumerated above would seem to portend a large expansion of the pipeline industry.

It is concluded that such pipelines, referred to here as freight pipelines, are most likely to materialize in two forms: 
slurry pipelines and capsule pipelines. As is discussed in depth in Report R-3023 of this series (see Table 1.1-1 above) the pressures for slurry pipelines are developing and the battle lines are drawn; hence they are not treated in this report. Capsule pipelines, on the other hand, may possess even more promising potential, but there is little likelihood that comparable pressures for them will develop without a DoE-sponsored program of research, development and demonstration. Further study of the concept is strongly recommended. 


\subsection{RECOMMENDATIONS}

In this brief analysis, it was not possible to perform quantitative performance comparisons or systems studies of the various concepts for freight pipelines and accordingly, such analysis was not attempted. Instead, an attempt was made, by an examination of all modes of freight transport and of the effects of modal shifts between them, to identify the general performance envelope into which they must fall if they are to be economically competitive. This analysis indicated that system technical performance objectives should include:

1 - Capability to accommodate both packaged freight of medium size and bulk commodities;

2 - An average speed of $20 \mathrm{mph}$ or more;

3 - Capability to ascend and descend steep grades;

4 - Capability of high throughput.

Requirement 1 calls for a capsule system. Requirements 2 and 3 determine capsule separation. Requirement 4 is determined by the economic analysis.

These requirements are in some ways contradictory. For example, requirement 3 calls for wide capsule spacing and limited speed, in contradiction to requirements 1,3 and 4 . Further study is required to examine these and other tradeoffs, and to identify a concept for analysis and possibly for an $R, D, \& D$ program.

In Report R-3025 of this series (see Table 1.1-1 above), the broad outlines were presented of the programs of research, development, and demonstration which are needed to realize the energyconservative potential of the technological innovations that were discussed in that report. In each case, the recommended program consists of the six phases described below: 


\section{Phase 1 - Identification of the Opportunity}

This phase has been in progress under the present study, and with the publication of this report is now complete.

Phase 2 - Concept Validation

In this phase the concept is validated analytically and a definitive program plan developed.

\section{Phase 3 - Research and Development}

The research and development identified under Phase 2 is performed in accordance with the approved R\&D plan. The R\&D program continues through the design phase (Phase 4) and possibly beyond.

\section{Phase $4-$ System Design}

A preliminary design is prepared of the demonstrator system on the selected site.

Subphase 4.1 - Site Selection - Several candidate sites are identified and the one best meeting the criteria developed under Phase 2 is selected.

Subphase 4.2 - Preliminary Design - A preliminary design is prepared of the demonstrator system on the selected site.

Subphase 4.3 - Detailed Design - The detailed design of the demonstrator, consisting of drawings and specifications suitable for use in construction, is prepared and documented, along with supporting design analyses. This subphase is paced by the progress of the research and development under phase 3 above, which will have been proceeding concurrently with Phase 4 .

\section{Phase 5 - Demonstrator Construction}

The demonstrator system is constructed. Data regarding construction costs, design feedback, and technological difficulties are collected, analyzed, and published in accordance with the program plan which was developed under Phase 2 . 


\section{Phase 6 - Demonstrator Operation}

The demonstrator system is operated in accordance with the program plan. Data regarding the operation is collected, analyzed, and published in accordance with the program plan.

The generic schedule for phase 2 of this program is presented in Fig. 3.0-1. It is strongly recommended that this next phase be implemented. If available resources cannot support the entire Phase 2 immediately, then at the very least, Subphase 1, opportunity confirmation, and a preliminary Subphase 5, Program Definition, should be performed. 


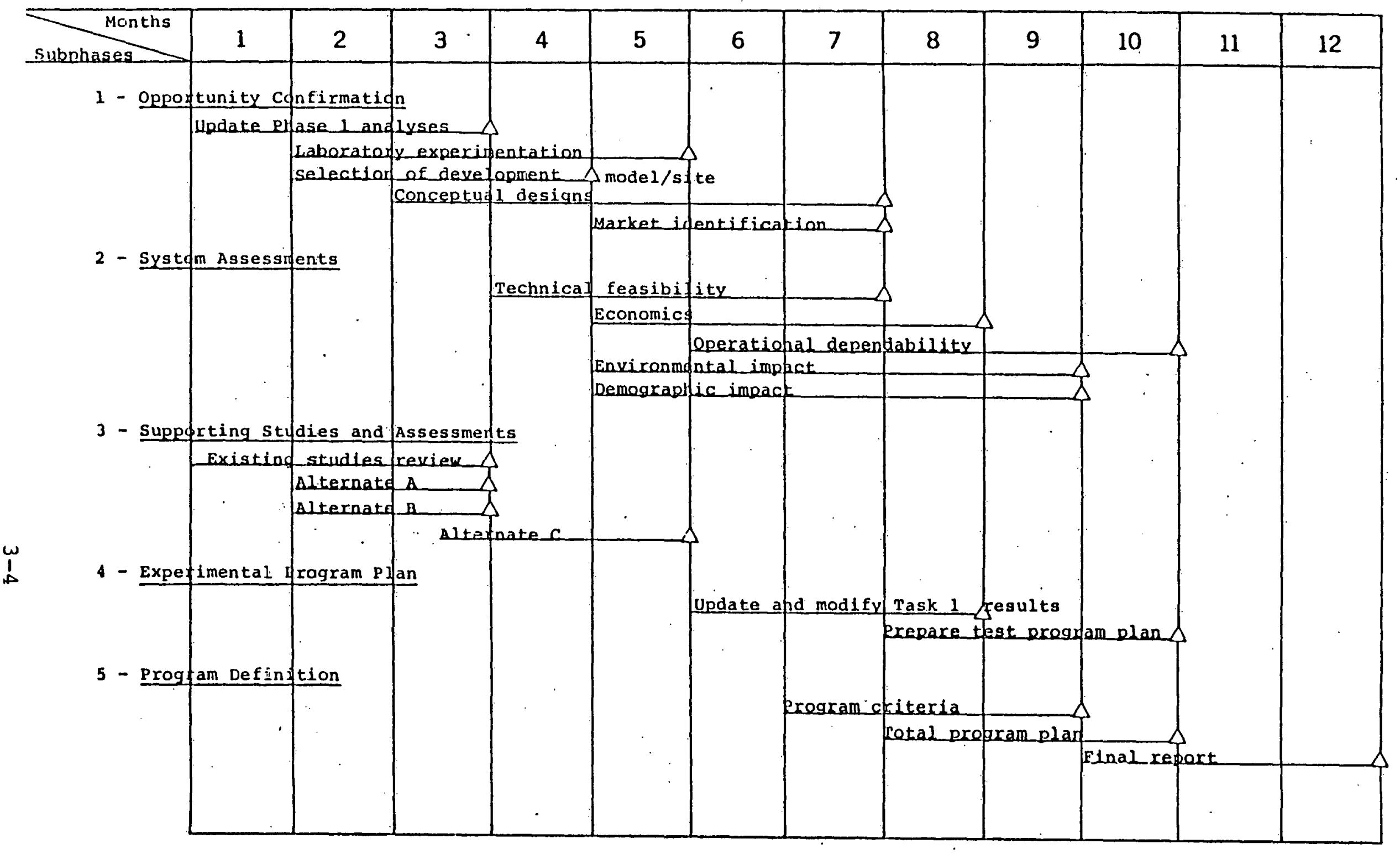

Figure 3.0-1 Generic Phase 2 Schedule 


\subsection{THE CONVENTIONAI SCENARIO}

In speculating about the future, it is useful to have a reference (baseline) case against which to make comparisons. For present purposes, it is convenient to take as the reference case a projection of the pipeline and petroleum industry future as the industry leaders would expect it to unfold. This projection may be inferred from the collection of papers contained in the Oil and Gas Journal's special commemorative issue, "Petroleüm/2000" of August 1977. Virtually all of these authors are experienced engineers in the pipeline industry and now hold senior management positions. Their collective judgement may therefore be regarded as the conventional wisdom.

The future of gas pipelines is discussed by Bowen [1977], who predicts that "... natural gas will supply about the same volume of energy in the year 2000 as it does today. Its percentage of the whole, however, will be considerably less (Fig. 1)." Figure 4.0-1, which is Bowen's Fig. 1, shows his projection of energy supply, while Fig. 4.0-2 shows his projection of gaseous fuel consumption.

Bowen's discussion relates only to natural gas. Privately, many people in the gas pipeline industry refer to their industry as a dying one. The American Gas Association (AGA) vociferously denies the validity of this characterization and adduces evidence to support its position that "the gas industry is taking action and is encouraging appropriate supporting government action to assure that gaseous fuel will be available in significant amounts well into the future" [Gibeaut 76]. The AGA projection is shown in Table 4.0-1 [Lawrence 77]. Of course, a great deal more can be said about gas supply and consumption in the future. The AGA's Gas supply committee maintains a continuing overview of the subject and publishes a monthly Gas 
THIS PAGE

\section{WAS INTENTIONALLY LEFT BLANK}




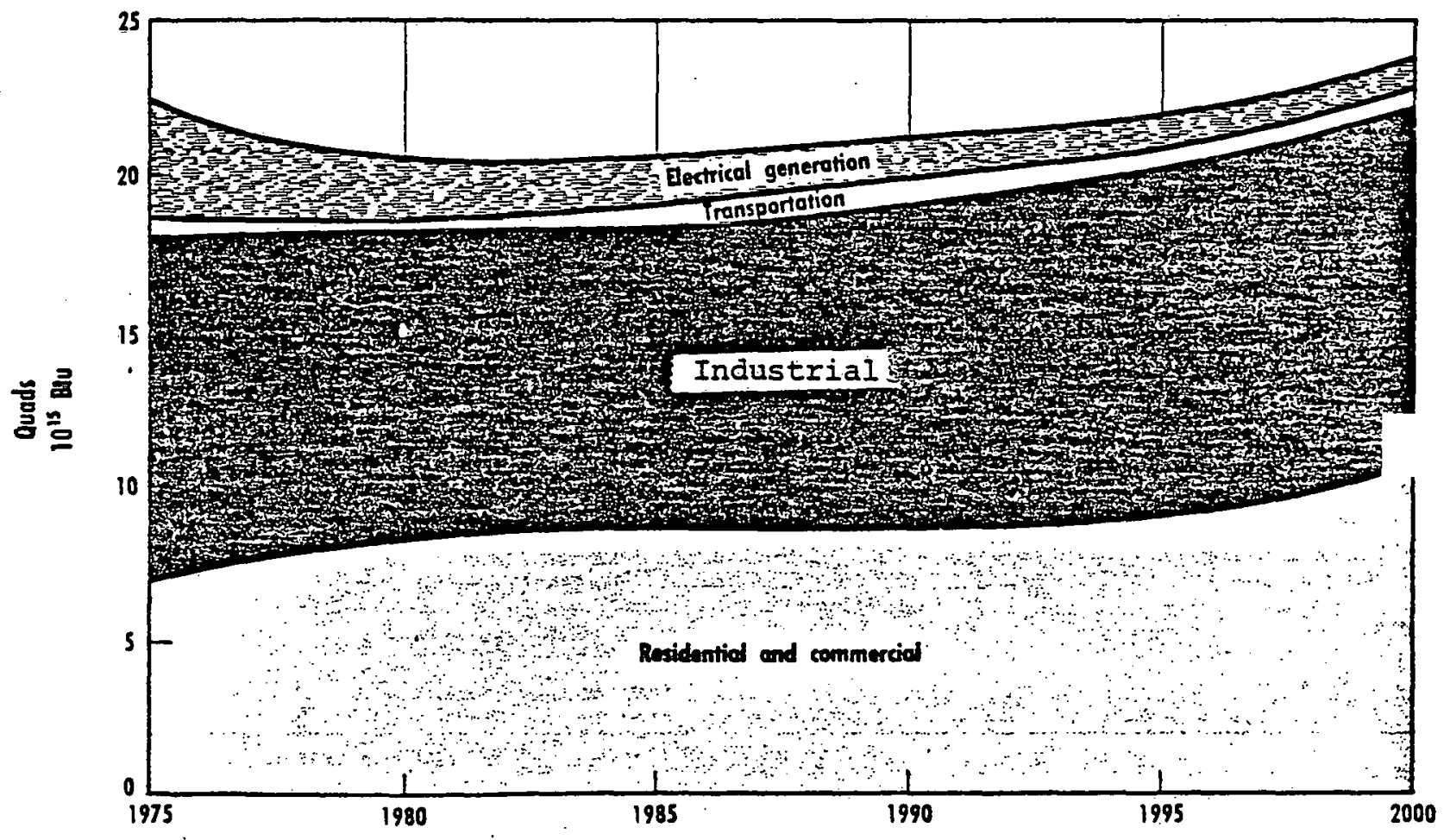

Source: Oil and Gas Journal (Bowen 77)

Fig. 4.0-2 - Energy consumption projection 
TABLE 4.0

AGA Projection of gas production under full deregulation ( $1012 \mathrm{scf} / \mathrm{hr})$

Conventional supplies (lower 48)

Supplemental supplies

Total production

\begin{tabular}{|c|c|c|c|c|c|}
\hline 1976 & 1980 & 1985 & 1990 & 1995 & 2000 \\
\hline 195 & 196 & 200 & 2001 & 190 & 180 \\
\hline 15 & 25 & 55 & 21 & 11.1 & 140 \\
\hline 207 & 221 & 25.5 & 28.2 & 30.1 & 320 \\
\hline
\end{tabular}

Source: Oil and Gas Journal (Lawrence 77) 
Supply Review. It is important to note that, while the Association takes umbrage at the suggestion that its industry is dying, even the projection of Table 4.0-1, which is optimistic in that it assumes full and immediate deregulation, assumes only a very moderate $(1.8 \%)$ annual growth.

From the foregoing and other available information, it is a conclusion of this study that the position of the Association is essentially sound. The American public will demand a continued supply of pipeline-quality gaseous fuel, and they will get it. The inevitable price increases to reflect the true economic cost of alternate gas supplies will occur and will result in an influx of synthetic gas. At the same time, however, there will be no significant overall industry growth in terms of total sales.

In the case of oil, a similar conclusion emerges. Figure 4.0-3 shows the projection of Granville [77] for U.S. crude production, and Fig. 4.0-4 shows his projection for supply and demand. The shortfall, beginning in 1985-1990, is also expected by Warner [77].

Now the fact that no significant growth in oil and gas production is projected does not mean that no pipelines will be built. All of these projections assume that new fields will be brought into production, and new pipelines will therefore be required. At the same time, however, traffic over many existing lines will diminish, as has in fact already occurred in many cases. Wacker [77] foresees that domestic crude pipeline construction will continue, but at a modest rate of about 1500$2000 \mathrm{miles} /$ year. In discussing the future of products pipelines, Jones [77] projects a growth in refinery output of $2.6 \%$ per year. Thus it seems unlikely that large amounts of new products pipeline mileage will be built, eertainly not if the nation is successful in limiting total consumption and oil imports. 


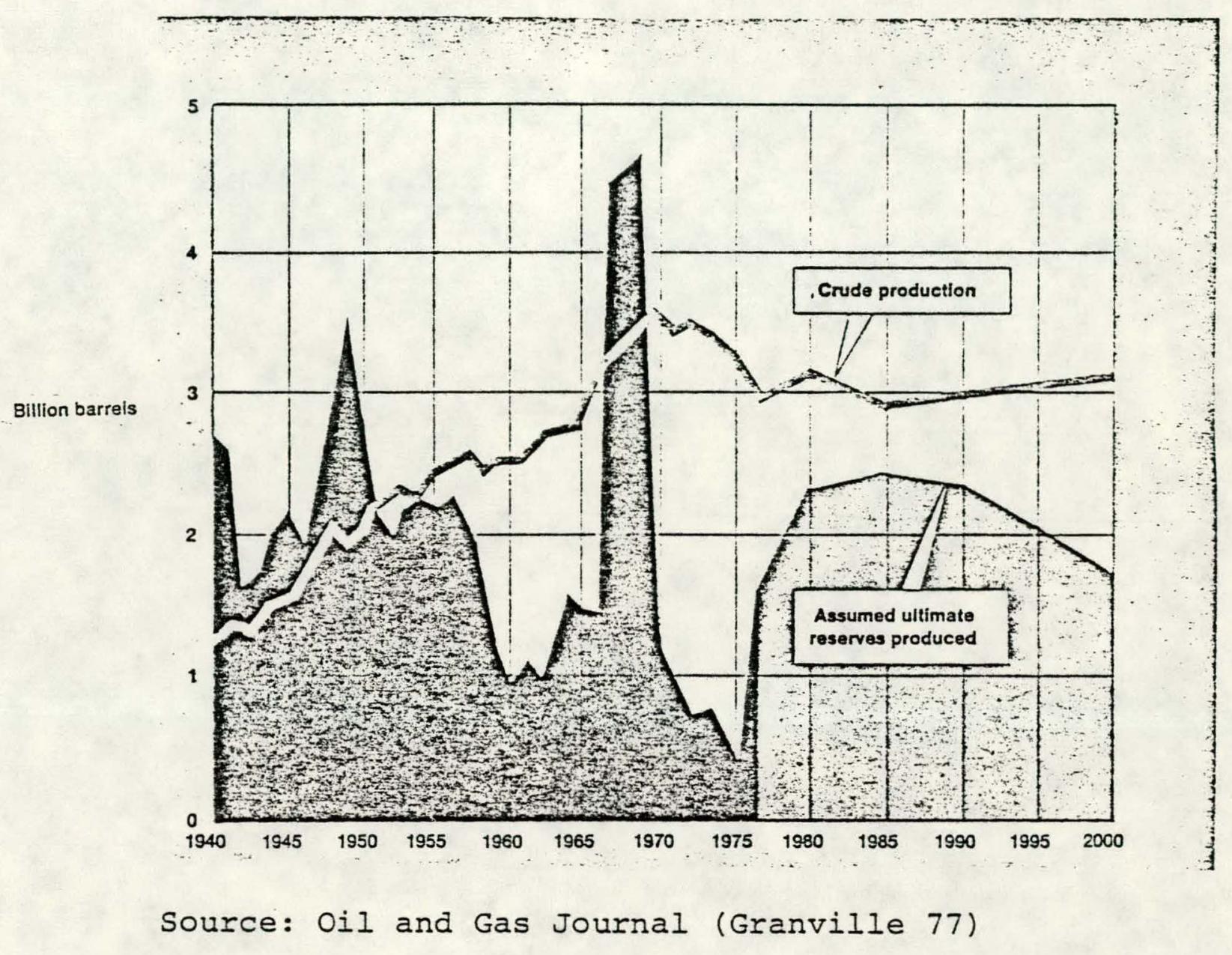

Fig. 4.0-3 - U.S. Crude production 


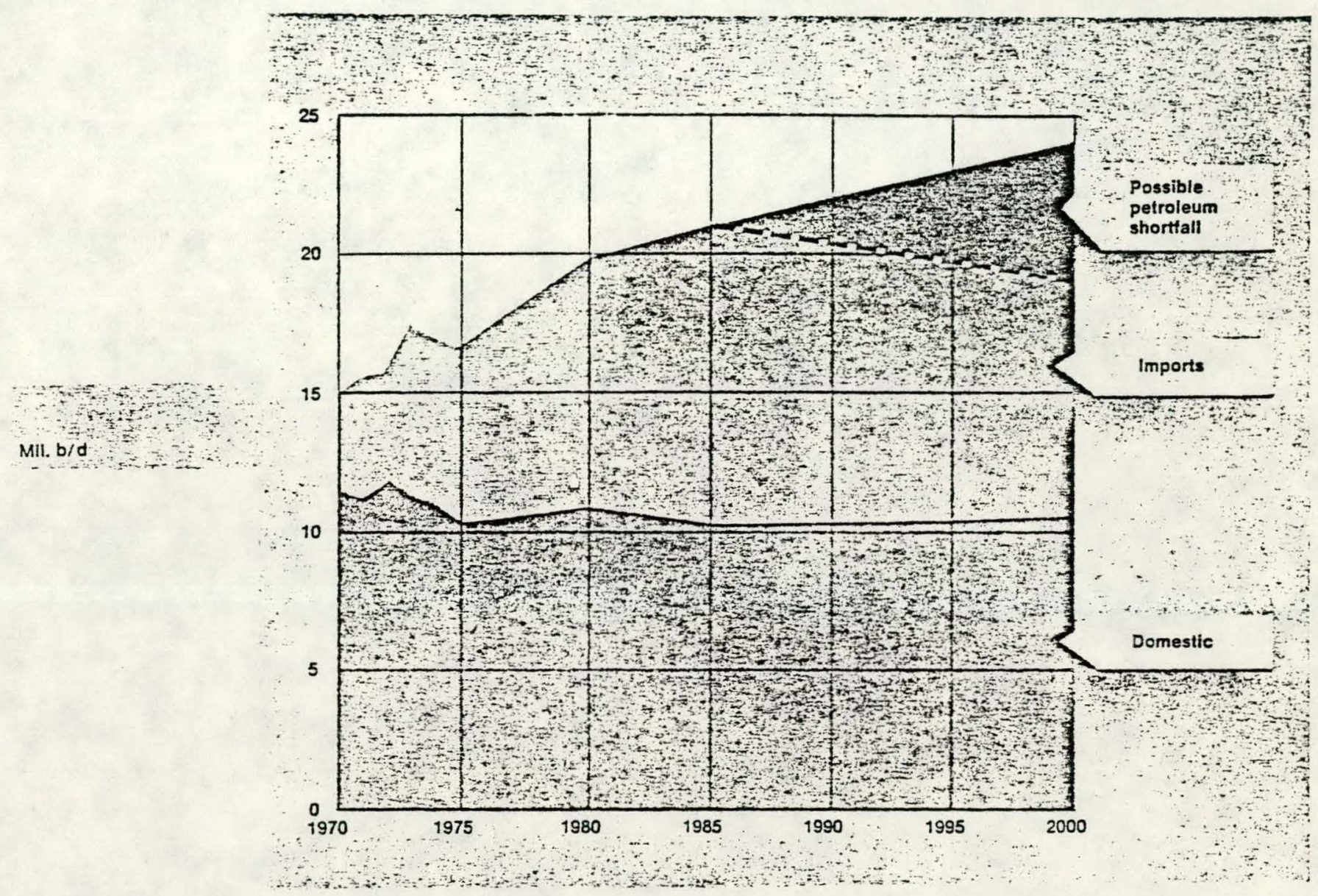

Source: Oil and Gas Journal (Granville 77)

Fig. 4.0-4 - U.S. petroleum supply and demand 
From these observations, two conclusions relative to the future of the pipeline industry that are significant for present purposes can be drawn. First, the total volume of gas and oil pipeline traffic will remain about level, or grow modestly through the rest of the 20th century. Second, on certain lines, traffic will decline and eventually some of these will be retired from service. If other uses for these systems than oil and gas transport could be found, the result would be a greater growth for the industry than the expectations aiscussea above.

These two general and nonquantitative conclusions constitute our reference case scenario for the future. 


\subsection{THE UNCONVENTIONAL SCENARIO}

In the preceding section, it was seen that in all of the scenarios which were identified as reasonable postulations, a large number of pipelines are likely to be retired from service in the years ahead. With this conclusion, it is only natural to inquire into the possibilities for using these idle systems for other, i.e., unconventional, purposes. And if conversion of existing pipelines is feasible, the next obvious question is whether new facilities for such purposes can be economically justified.

Unconventional pipelines have been studied and built for many years. Coal slurry lines are the most visible example, because the first such system was placed in operation on a large commercial scale 20 years ago. There are numerous smaller slurry lines around the world which move various minerals [Gray 75]. It would also be possible to use pneumatic slurries.

Besides slurrying in a liquid or gas, it is also possible to move solid material through pipelines by means of capsules. Capsules may be propelled in a number of ways, e.g., pneumatically, hydraulically, or electrically, and they may or may not roll on wheels and/or tracks within the pipe. For the purposes of this discussion, all of these variations of slurries and capsules will be considered together under the general term of freight pipelines.

The history and technology of freight pipelines will be discussed later, in section 6.0. The present discussion simply postulates technical and economic feasibility for pipelines which can transport both bulk and packaged goods over long distances, and then examines the energy consumption consequences of such services and their marketability. The point of departure for the discussion is a comparative examination of the energy intensity of freight transportation modes. 


\subsection{The Price of Speed}

The energy intensity of a transportation vehicle is the energy that is consumed in moving unit mass of the vehicle over unit distance. In general, this energy consumption consists of acceleration and braking energy, changes in potential energy which result from elevation changes over the route, and the energy to overcome frictional resistance to motion. This latter element is generally by far the largest, and it is thus instructive to compare its magnitude for various transportation modes.

The earliest and apparently still the most comprehensive comparison of vehicular motion resistance appears to be that of Gabrielli and von Karman [1950], from which Fig. 5.1-1 is taken. They observed that the dashed straight line in the figure appears to constitute a limit upon vehicle performance. In Fig. 5.1-2, they have plotted the single-vehicle specific power, again noting the existence of the apparently limiting line.

Figures 5.1-3 and 5.1-4 present their corresponding curves of motion resistance and specific power for convoys. The limiting lines for single vehicles which were inferred from the previous two figures have also been plotted here. An order of magnitude performance improvement is seen to be realized as a result of convoying, particularly in the case of the railroad, a point which will be important in the discussion to follow.

Gabrielli and von Karman were interested in the possibility of expressing the performance limit, reflected by the limiting line in the figures, as a general law. They pointed to the dimensionless quantities, e.g., Reynolds number, Froude number,etc. which characterize the resistance laws of media through which the vehicles move. Recognizing that speed limitations upon vehicles arise through relationships between resistance of the medium and strength of the vehicle structure, they attempted to relate the rupture length (lergth of a vertically hanging rod which would break under its own weight) of the vehicle structural 


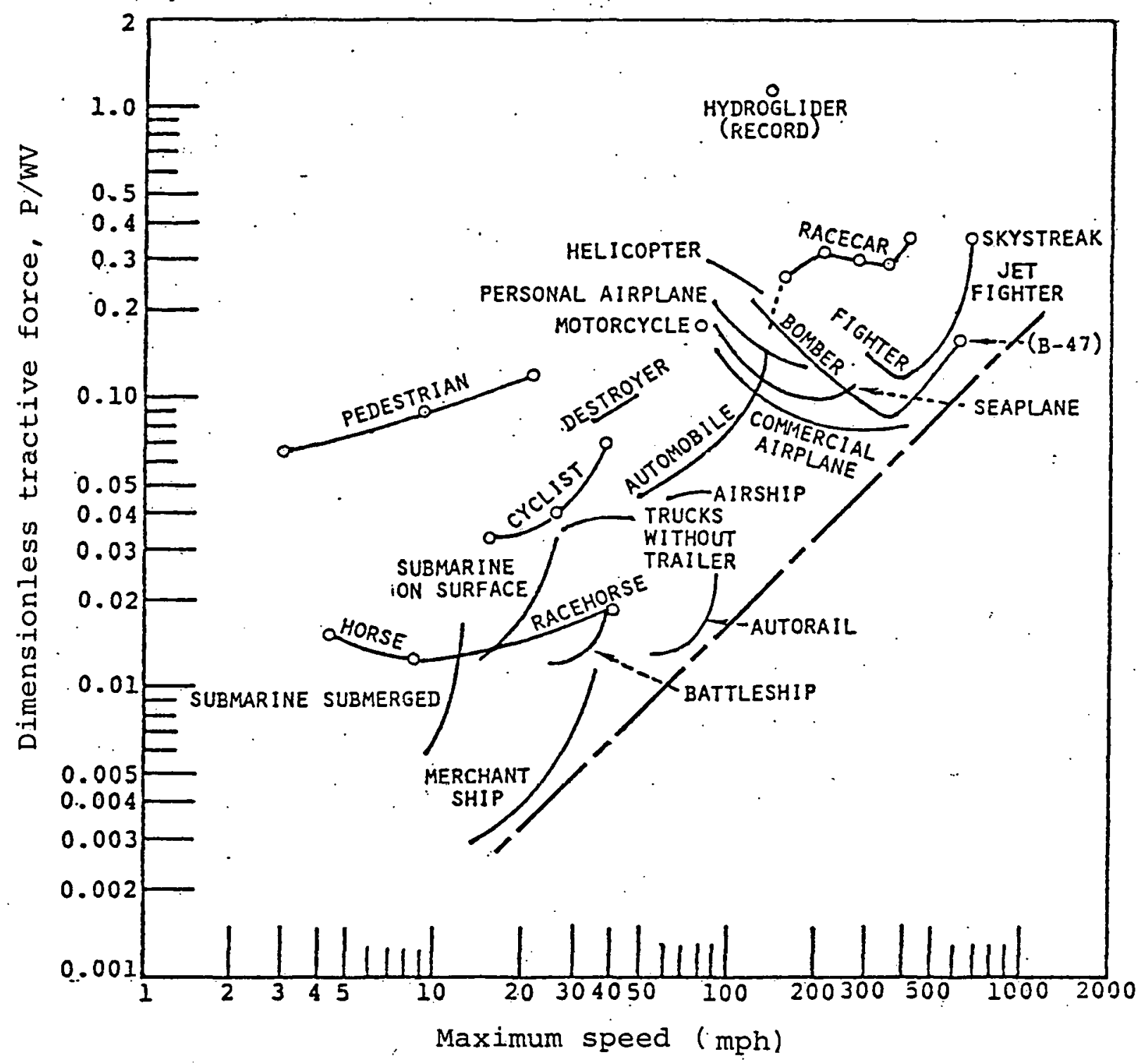

Notation: $P \triangleq$ power, ft-lb/sec

$\mathrm{W} \triangleq$ vehicle gross weight, lb

$\mathrm{V} \triangleq$ vehicle speed, $\mathrm{ft} / \mathrm{sec}$

Source: Gabrielli and von Karman (1950)

Fig. 5.1-1 - Single-vehicle motion resistance 


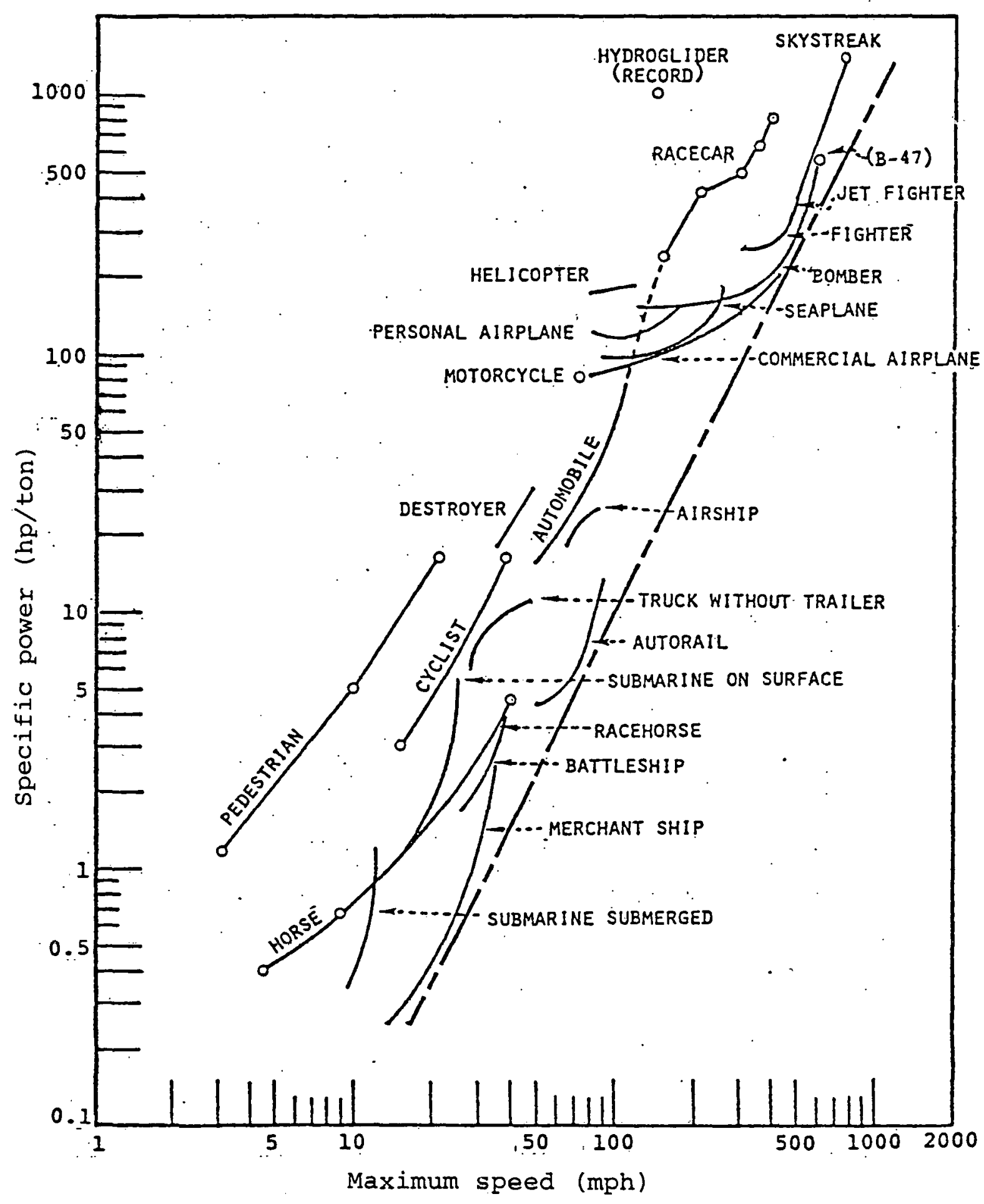

Source: Gabrielli and von Karman (1950)

Fig. 5.1-2 - Single-vehicle specific power 


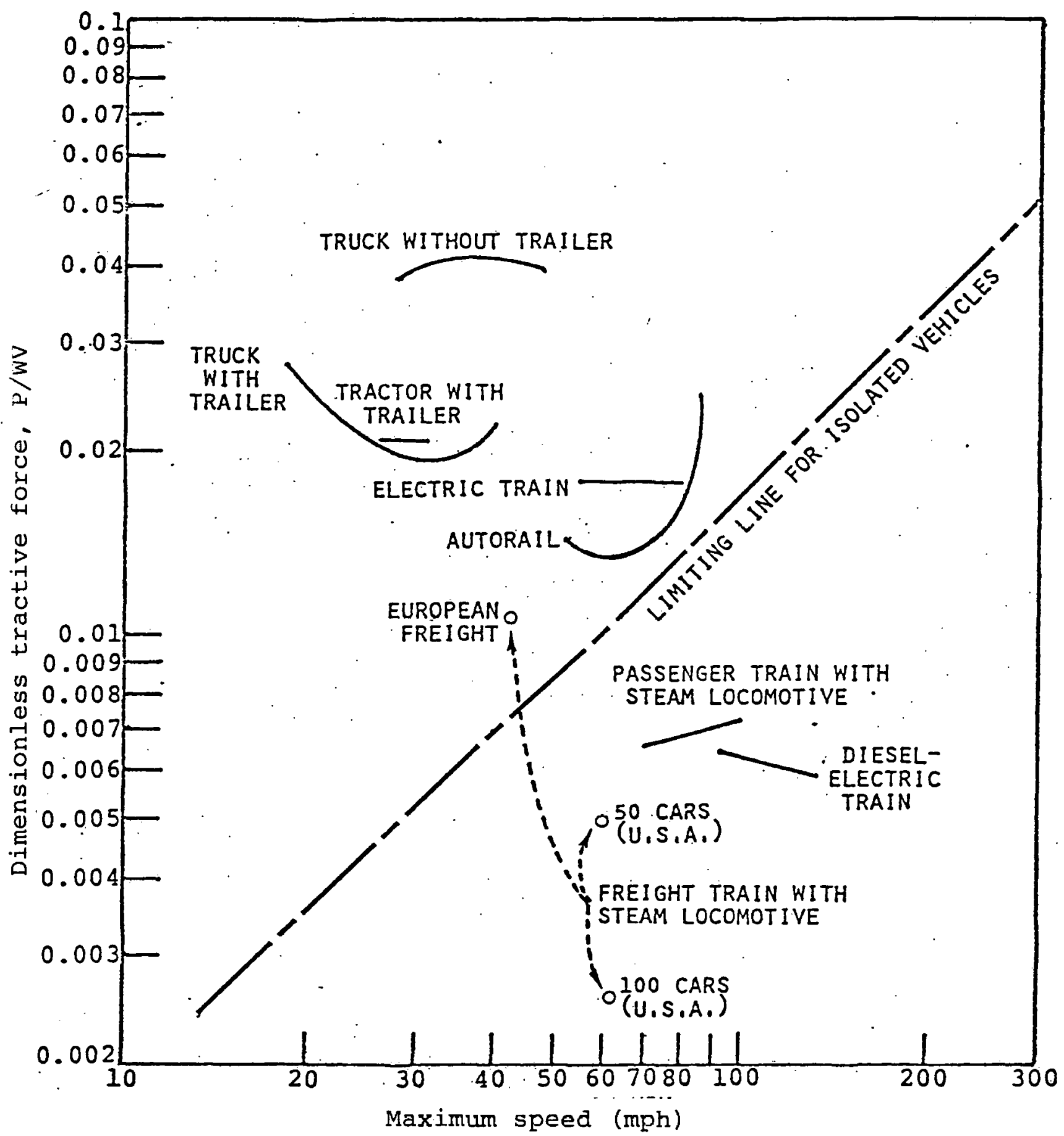

Source: Gabrielli and von Karman (1951)

Fig. 5.1-3 - Motion resistance of convoys 


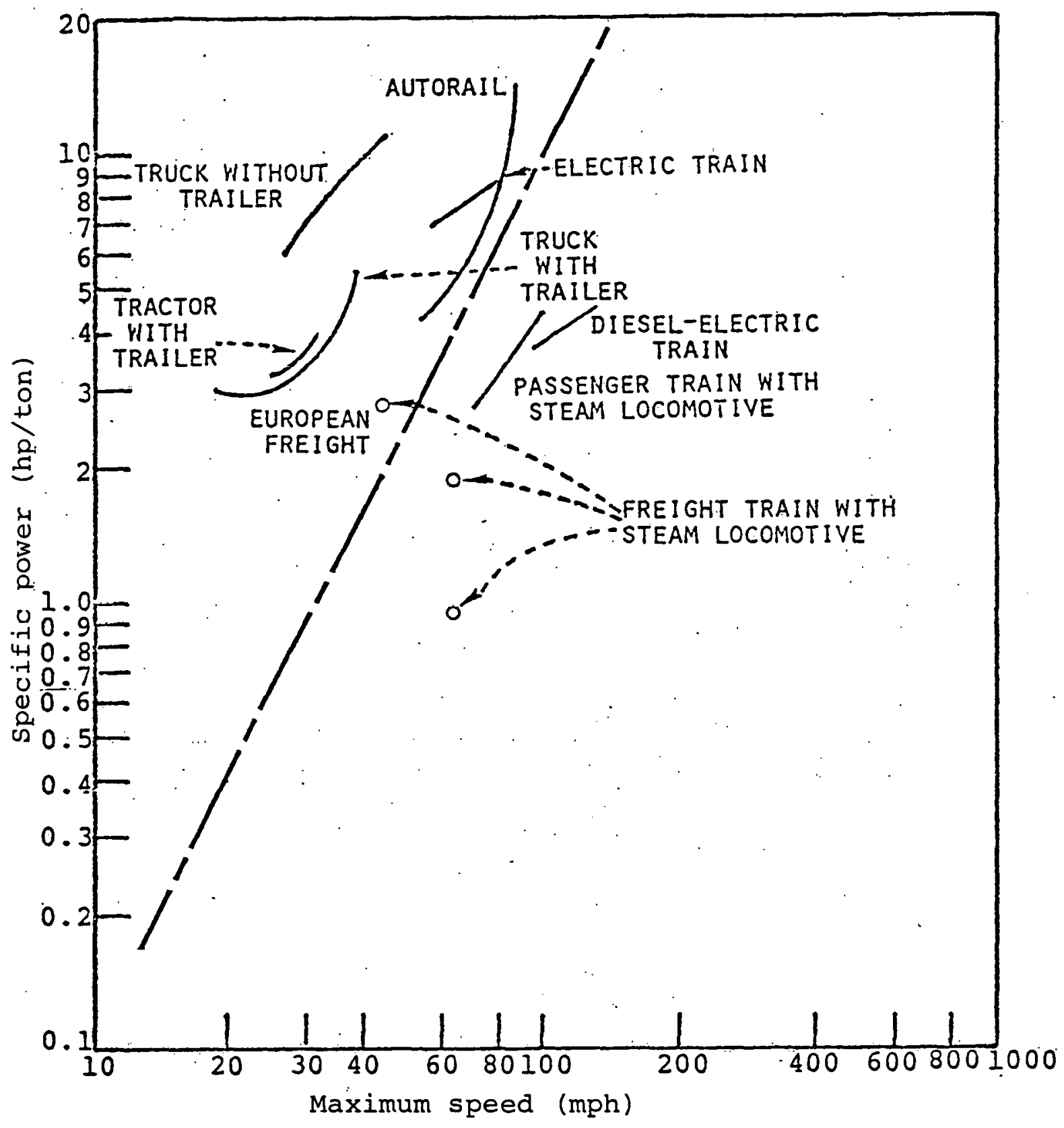

Source: Gabrielli and von Karman (1950)

Fig. 5.1-4 - Specific power of convoys 
material to motion resistance parameters.

Denoting the rupture length as $L$, they defined the dimensionless structural characteristic of the vehicle as

$$
\mathrm{N}_{\mathrm{st}} \triangleq \frac{\rho g L}{\sigma_{u}}
$$

where

$$
\begin{aligned}
& \rho \triangleq \text { density of the structural material } \\
& g \triangleq \text { acceleration of gravity } \\
& \sigma_{u} \triangleq \text { ultimate stress of the material. }
\end{aligned}
$$

This number characterizes the ratio of maximum vehicle length to rupture length of the material. Eliminating $I$ between this parameter and the Froude number $V / \sqrt{g L}$, they obtained the new parameter

$$
\frac{\mathrm{V}}{\sqrt{\sigma_{\mathrm{u}} / \rho}}
$$

which represents the ratio of vehicle speed to a speed which is a characteristic of the material, being the circumferential linear speed at which a thin ring would centrifugally disintegrate.

Speculating further that the Young's modulus $E$ of structural materials may dominate the performance of vehicles, Gabrielli and von Karman noted a surprisingly small variation in the two characteristic speeds, $\sqrt{\sigma_{u} / p}$ and $\sqrt{E / p}$, for the materials which they listed in Table 5.1-1. For comparison, some values presented in Table 5.1-2 were taken from engineering handbooks and other sources 25 or more years later.

This line of investigation appears not to be particularly fruitful, although its usefulness will be seen later in a 
TABLE 5.1-1

Comparison, $\sqrt{\sigma_{\mathrm{u}} / \rho}$ and $\sqrt{\mathrm{E} / \rho}, 1950$

$\begin{array}{lccc}\text { Material } & \begin{array}{c}\sigma_{\mathrm{u}} \\ 13^{\sigma_{\mathrm{u}} / \rho}\end{array} & \begin{array}{c}\sqrt{\mathrm{E} / \rho} \\ \mathrm{fps}\end{array} & \mathrm{fps} \\ \text { Structural steel } & 80 & 870 & 16,800 \\ \text { Stainless steel } & 80 & 875 & 16,600 \\ \text { Heat-treated steel } & 150 & 1190 & 16,800 \\ \text { Duval 24 S-T } & 65 & 1320 & 16,650 \\ \text { Titanium, 1950 } & 120 & 1410 & 15,800 \\ \quad \begin{array}{l}\text { production } \\ \text { Titanium, projected }\end{array} & 180 & 1725 & 15,800\end{array}$

Source: Gabrielli and von Karman (1950) 


\section{TABLE 5.1-2}

Comparison, $\sqrt{\sigma_{u} / p}$ and $\sqrt{E / P}, 1975-77$

\begin{tabular}{|c|c|c|c|}
\hline Material & $\begin{array}{l}\sigma_{\mathrm{u}} \\
10^{3} \mathrm{psi}\end{array}$ & $\begin{array}{c}\sqrt{\sigma_{u} / \rho} \\
\text { fps }\end{array}$ & $\begin{array}{l}\sqrt{E / \rho} \\
\text { fps }\end{array}$ \\
\hline Steel, low carbon & 60 & 7.50 & 16,500 \\
\hline Steel, stainless 316 & 90 & 910 & 16,100 \\
\hline $\begin{array}{c}\text { Steel, API, 5LX-65 } \\
\text { (pipeline) }\end{array}$ & 90 & 920 & 16,400 \\
\hline Aluminum 5086, H34 & 47 & 1140 & 16,900 \\
\hline Magnesium, $\mathrm{ZK} 60 \mathrm{~A}$ & 52. & 1453 & 16,200 \\
\hline Titanium (6Al4V) & 155 & 1610 & 16,200 \\
\hline Wood, fir & 6.3 & 1110 & 16,900 \\
\hline Nylon 66 & 11.8 & 880 & 16,400 \\
\hline Epoxy, wound & $80-250$ & 2330 & - \\
\hline
\end{tabular}

Sources: Liley (1976), Singer (1975), Mihelich (1977) 
somewhat different context. The primary reason lies in the fundamental differences in the physics of the different modes of locomotion. For example, the Froude number is related to the resistance encountered by a ship due to its generation of waves. There is no obvious reason to suppose that a parameter which relates a vehicle's structural strength to its Froude number in the water would influence its speed on land or in the air. At the same time it is intuitively clear that the primary price of speed is always specific power, and that the power which can be carried on board is limited by the strength-to-weight ratio of the vehicle structure.

Bekker [1956] was also interested in the characterization of speed limitations. However, he approached the subject differently, beginning with analysis of the physics of the different locomotion processes, as distinquished from the statistical correlation attempted by Gabrielli and von Karman.

The equations developed by Bekker reveal interesting differences in the price that is paid for speed by the various locomotive modes. The power law dependencies of modal specific power upon speed are listed in Table 5.1-3. It is interesting to observe that the animal modes power consumption rises only as the first power. Figure 5.1-5 shows Bekker's plot of specific power. In the flow regime, he only considered rivers, i.e., open channel flow, but the near-third-power dependence which obtaing for vehicles passing through fluid media at moderate speeds gives his chart a broader significance. The third-power dependency is, as indicated, only approximate. since the actual dependency is governed by coefficients which are nonlinear functions of Reynolds number. It must be recognized that the specific power of channel or pipe flow is for cargo only, whereas for the other modes the horsepower per ton refers to the gross vehicle weight. Payload specific power for those modes is therefore much higher than the values indicated in the figures. 


\section{TABLE $5.1-3$}

\section{Power-law dependence,} specific power vs. speed

\begin{tabular}{lc}
\multicolumn{1}{c}{ Mode } & $\begin{array}{c}\text { Power law } \\
\text { exponent of speed }\end{array}$ \\
Quadruped running & 1 \\
Crawler & 1 \\
Slider & 1 \\
Biped walking & 1 \\
Hard wheel on hard surface & 1 \\
Liquid flow & $\sim 3$
\end{tabular}




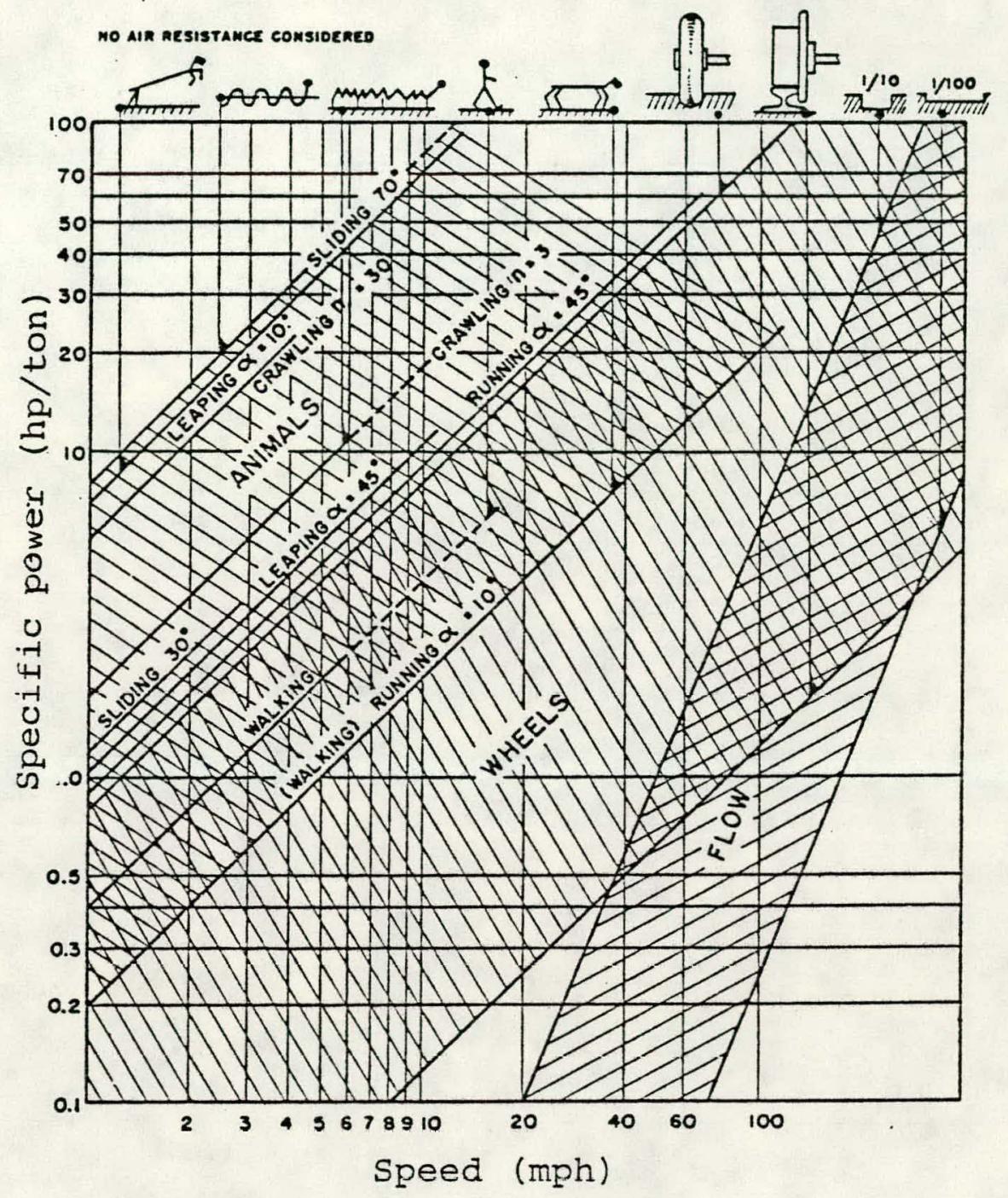

Source: Bekker (1956)

Fig. 5.1-5 - Specific powers of land on fluid medium transport modes 
Now, while the attempts to identify a universal law of limitation of vehicle performance have not been successful, they have nevertheless served to illustrate some points of interest. First, even though there may be no universal law governing the price of speed in terms of energy, the Gabriellivon Karman plots show that for single vehicles, whatever the nature of the limiting influences in the various regimes, they are quite consistent. The limiting line appears to exist, though in the absence of a rationale, that consistency across different regimes must be presumed coincidental. Second, the advantages of convoys were dramatically illustrated in Figs. 5.1-3 and 5.1-4. Taken together, these observations suggest an approach to optimization of the allocation of freight among the transport modes, a subject which will be developed in the next section.

\subsection{Characterization of the Modal Mix}

The primary interest of this study is energy conservation; hence a most important objective of the optimization process is minimizing energy consumption. In the preceding discussion, comparisons were drawn between the characteristic motion resistances of transport vehicles, with particular attention to the on-board specific power, i.e., hp/ton. However, for purposes of energy conservation, a preferred index is the onergy intensity (EI or $I_{Q}$ ) ${ }_{i}$ The approach here will be to estimate the EI for the five principal freight transport modes, characterize them as the price paid for speed in terms of energy, and attempt to identify modal shifts which might reduce overall energy consumption.

The EI may be defined as the dimensionless ratio of the foot-pounds of energy consumed in moving a pound of freight through a distance of one foot. That is, it is the ratio of transportation work used in overcoming resistance to the useful work of moving the goods. However, a more commonly used unit is the Btu/ton-mile. 
Report R-3022 of this series (see Table 1.1-1 above) discusses the methodology of calculating the EI for pipelines and presents estimates of the EI for the various types of pipeline. Table 5.2-1 lists these estimates along with average speed and average tariff for the five principal freight transport modes. In Fig. 5.2-1 the energy economy (inverse of energy intensity) from the table is plotted against the average modal speed, along with the regression line. The next step in the optimization analysis is to define a criterion of merit.

\subsection{A Criterion of Merit}

The reader will already have reflected that, since the scales on both axes of Fig. 5.2-1 were so chosen that desirable increases are in the outward direction, improving performance is reflected on the chart by increasing distance from the origin. And if the scales should happen to reflect equal values, then downward sloping lines at 45 degrees would represent Iines of equal performance. That is, suppose that the scales were such that one unit of energy economy were equal in value to one unit of speed. Then all systems on the 45 degree line would have the same energy-speed product, which could then be defined as the transportation figure of merit.

While further pursuit of this idea appears interesting, it is beyond the scope of this study. Its importance for present purposes derives from the fact that it allows us to generalize about the relative performance merits of the different modes. Some observations can now be made.

First, whatever value judgements one may place upon the two axes, the regression line represents average industry performance. Suppose, for example, that an entirely new transportation mode were introduced. If its speed-energy product fell anywhere on the regression line, it could be asserted that 
TABLE 5.2-1

Estimated average parameters for transport modes

\begin{tabular}{|c|c|c|c|c|c|c|}
\hline & Speed & $\mathrm{E}$ & (1) $\frac{\mathrm{Bt}}{\mathrm{T}}$ & $-M i$ & & $\begin{array}{l}\mathrm{EE}^{(2)} \\
\left(\mathrm{S}^{3}\right) \\
\text { Ton-Mi }\end{array}$ \\
\hline & (mph) & $\overline{\mathrm{P}-\mathrm{M}}$ & ORNL & $\overline{\mathrm{PI}}$ & $\mathrm{s}^{3}$ & $\overline{105 B t u}$ \\
\hline Pipeline & 3.2 & $\begin{array}{c}158 \\
(281)\end{array}$ & 565 & 550 & 350 & 286 \\
\hline Barge & 5.4 & 272 & 1404 & 500 & 380 & 263 \\
\hline Rail & 20 & 687 & 641 & 700 & 672 & 149 \\
\hline Truck & 45 & 2343 & 8485 & 2311 & 2825 & 35.4 \\
\hline Air & 500 & 39,949 & 56,965 & 29,600 & 56,700 & 1.764 \\
\hline (1) Energy & Intens & & . & & & \\
\hline (2) Energy & Economy & & & & & \\
\hline
\end{tabular}






Figure 5.2-1 Energy Economy of Transportation Modes 
the new mode offered performance equivalent to the industry average. This line of argument was advanced by Shure et al. [1973] in suggesting development of air cushion vehicles (ACV's) to serve the market between truck and air freight.

Second, in the sense discussed above, the railroad is the best performer. It lies farthest from the regression line, on the desirable side of the line, indicating that, on average, it offers a better speed-energy product than any other mode:

\subsection{Optimization of the Modal Mix}

This latter observation leads naturally to the question of how this performance superiority could be exploited to effect an overall reduction in energy consumption. A possible answer is illustrated in Fig. 5.4-1. This figure is the same as the preceding one, with the addition of postulated future points for the rail and pipeline modes. Two postulations have been made which are listed below and then discussed:

1) High-speed (130 mph in the figure), lightweight freight trains have been introduced. This innovation is indicated by the dashed line from the present rail performance, point (1) in the figure, to point (3). The intermediate point (2) will be explained later.

2) Freight pipelines, i.e., pipelines which transport solid freight, have been introduced. This innovation is indicated in the figure by the dashed line from the present pipeline performance, point (4), into the vicinity of present rail performance, point (1).

Postulation ( 1 ) is seen as reasonable for two reasons. First, Hopkins [1975] has shown that some increase in train speed would result in an increase in fuel economy, rather than a decrease as might be expected. Figure 5.4-2 presents one of his results. 


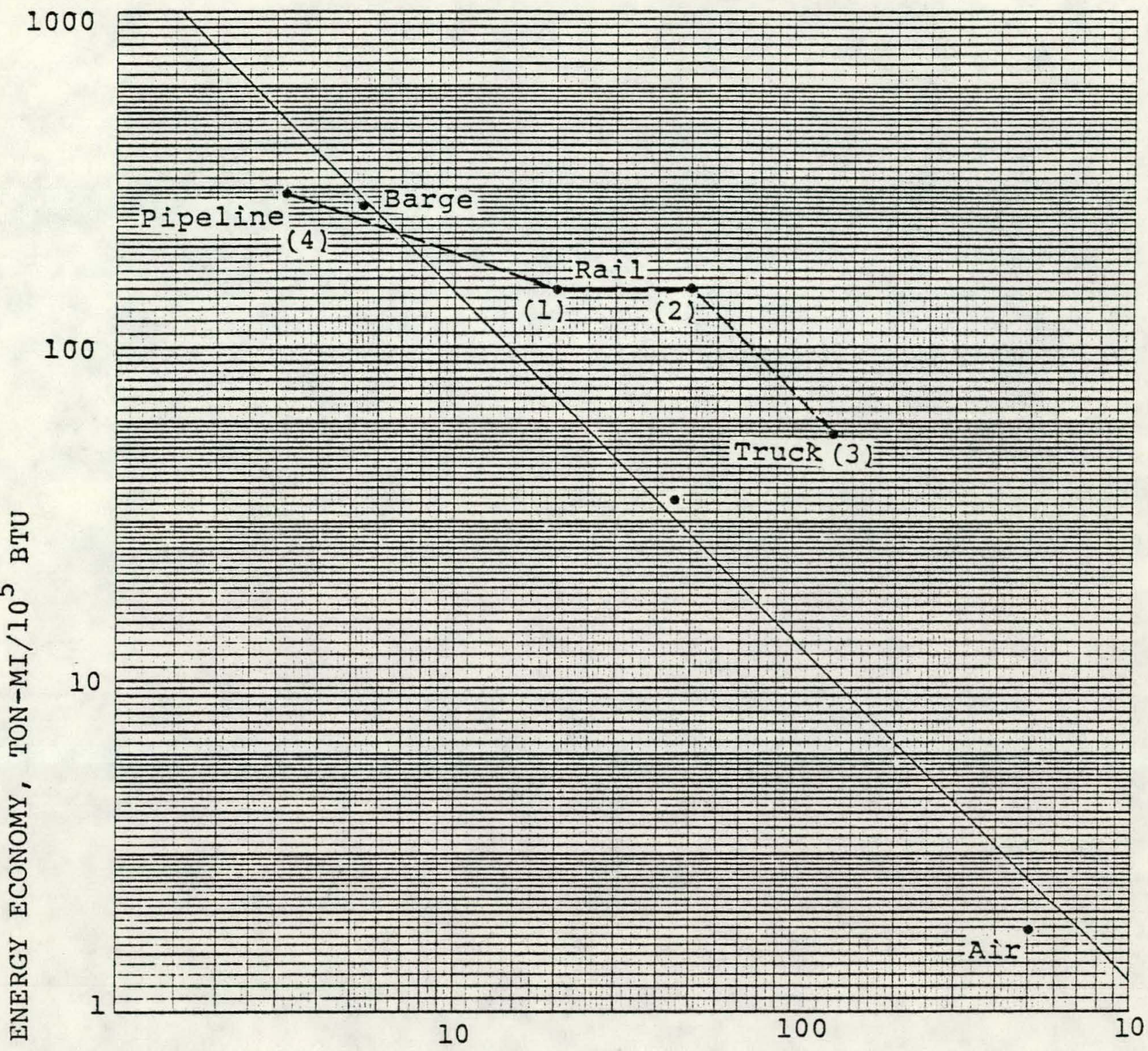

MODAL SPEED, MI/HR

Figure 5.4-1 Improvement of the Modal Mix 


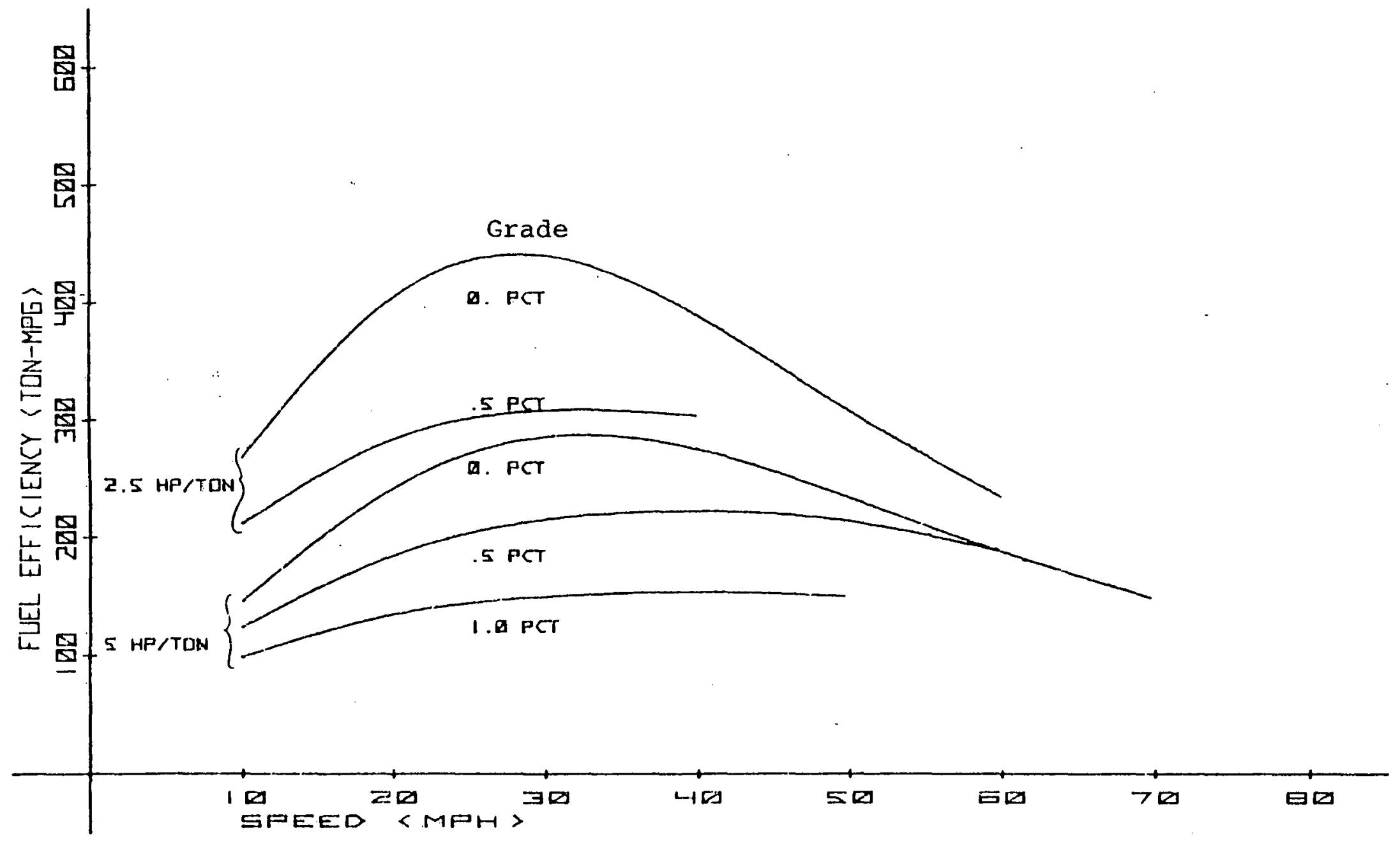

Fig. 5.4-2 - Rail fuel efficiency vs. speed [Hopkins 75] 
Setting aside for the moment any reservations regarding the representativeness of these results, one may observe that it is not necessarily unreasonable to project a substantial increase in average rail speed without energy penalty. Rail speeds in the United states are generally restricted by the condition of the track and seldom by the limitations of the equipment. Figure 5.4-2 indicates that the locomotive equipment operates more effectively at 30 to $40 \mathrm{mph}$ than it does at $20 \mathrm{mph}$, which is not surprising. Thereafter, aerodynamic effects become important, and efficiency decreases until at about $50 \mathrm{mph}$ it is about equal to what it was at $20 \mathrm{mph}$. With this observation in mind, point (2) on Fig. 5.4-1 is seen to indicate generally what might be done with rail transportation by enabling speeds in the neighborhood of $50 \mathrm{mph}$. This improvement requires a great deal of upgraded, and some new, roadbed but no new rolling stock or other equipment, and hence no new technology.

Point (3) on Fig. 5.4-1 indicates the performance region to which rail transport might be transformed by the introduction of new equipment, along with further roadbed improvements, to enable speeds in the range of $125-150 \mathrm{mph}$. Point (3) is at the intersection of the postulated $130-\mathrm{mph}$ speed and a line parallel to the regression line. This construction simply postulates that speed can be increased above the $50 \mathrm{mph}$ of point (2) in ways that are as energy efficient as the present industry average energy performance, which is represented by the regression Iine. This innovation does not require development of new technology, but does require introduction of existing technology from abroad, since that is where all the existing high-speed trains are.

Postulation (2) represents the freight pipeline innovation, which would absorb at least part of the heavy, slow-speed rail traffic. As noted earlier, it is indicated on Fig. 5.4-1 by the line from present pipeline performance over into the general vicinity of persent rail performance. Unlike postulation (I), which requires no new technology, though a very large capital investment, postulation (2) requires a large amount of both. It is 
therefore of interest to briefly examine the economics of the two postulations before proceeding to consideration of the technology development. 


\subsection{Modal Economies}

In Fig. 5.5-1, the dollar economy of the modes is presented, where the inverse tariffs from Table 5.5-I have been plotted against speed. As before, the desirable region of the chart is outward, and the product of the $x$ and $y$ coordinates of any point constitute a figure of merit for any system represented by that point. The numbered points on the figure correspond to the same two postulations which were described in the preceding section. Under postulation (1), it seems reasonable to further postulate a tariff increase (dollar economy decrease) for the rail which goes parallel to the regression line of average industry performance. The dashed line from point (1), present rail performance, to point (3), projected rail performance, represents this transition. The intermediate point (2) which appeared on Fig. 5.4-1 needs no counterpart here.

Similarly, it is postulated that the pipeline dollar economy moves from its present performance, point (4), to the vicinity of present rail performance, point (1). Both of these changes involve substantial gains, i.e., factors of five or six, in unit revenue.

To generalize further would require a great deal of additional analysis, which would be much beyond the scope of the present study. At this point, the somewhat surprising conclusion has tentatively emerged that with available technology, it may be economically feasible to run the freight trains five or six times faster than at present, and that if they did so, a tariff five or six times greater would be as close to average industry dollar-speed economy as at present. Also, if freight pipelines can be developed to assume the slower and heavier traffic thus vacated by the rails, the average freight pipeline tariff could possibly be five or six times greater than the present liquid pipeline tariffs. With these notions in mind, the 


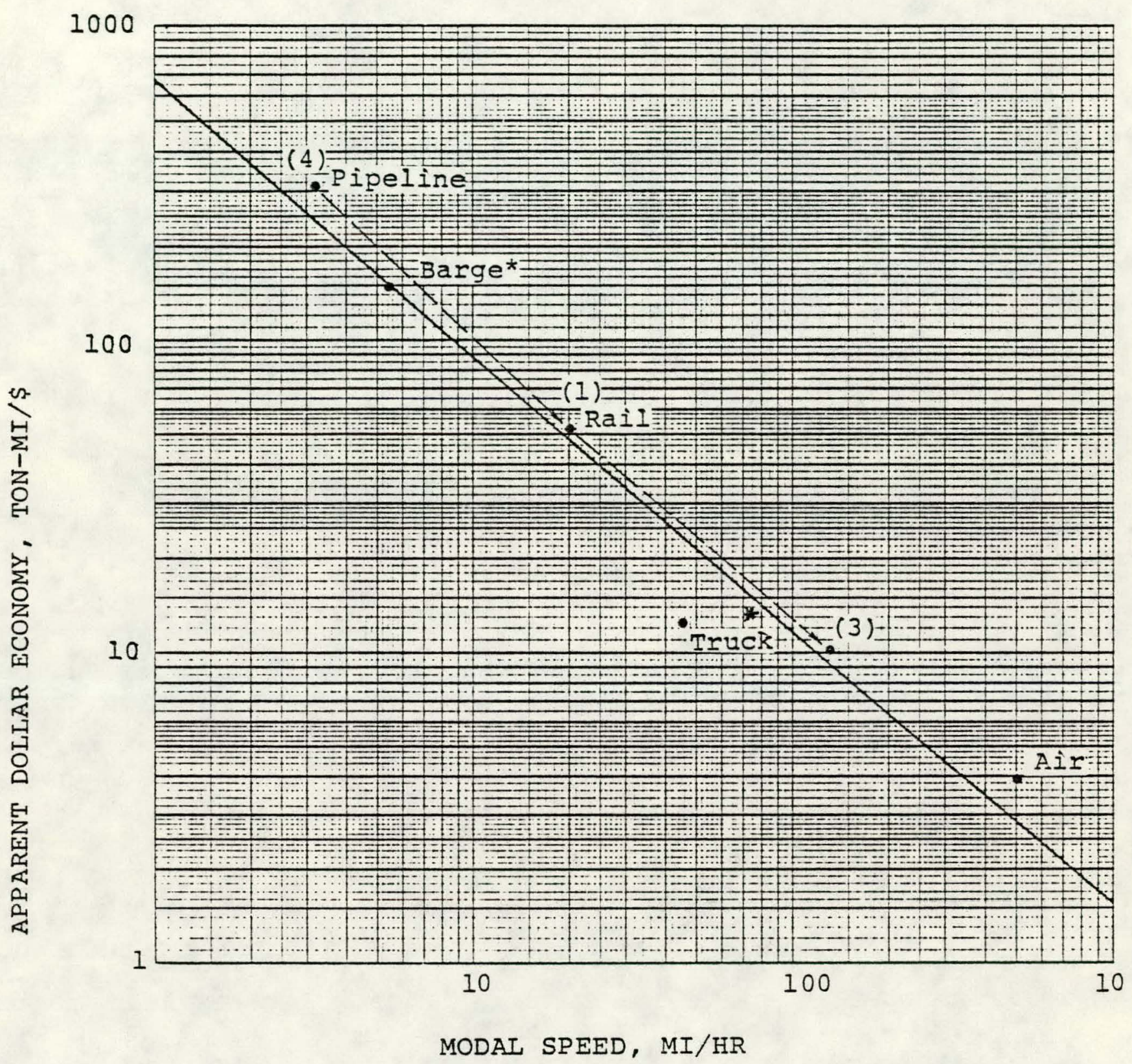

* Cost of Subsidy Not Included

Figure 5.5-1 Apparent* Dollar Economy of Transportation Modes 
TABLE 5.5-1

Inverse tariffs of transportation modes

\begin{tabular}{|c|c|c|c|c|c|}
\hline \multicolumn{4}{|c|}{ Oil Shipments } & $\begin{array}{c}\text { All } \\
\text { Shipments }\end{array}$ & $\begin{array}{l}\text { Avg. } \\
4 \& 5 \\
\end{array}$ \\
\hline$\frac{1974 \text { Tariffs }}{\text { Range }}$ & $\frac{\$ / 100 \mathrm{~B}-\mathrm{Mi}}{\text { Geometric }}$ & $\begin{array}{l}1974 \text { Tariff, } \\
\$ / \mathrm{T}-\mathrm{Mi}\end{array}$ & \multicolumn{3}{|c|}{$\begin{array}{c}\text { Inverse Tariffs } \\
\text { Ton-Mi/\$ }\end{array}$} \\
\hline (1) & $(2)$ & $(3)$ & $(4)$ & $(5)$ & (6) \\
\hline $2-10$ & 4.47 & 0.00320 & 312 & 298 & 305 \\
\hline $\begin{array}{l}5-10 \\
5-20\end{array}$ & $\begin{array}{l}7.07 \\
10.0\end{array}$ & $\begin{array}{l}0.00505 \\
0.00715\end{array}$ & $\begin{array}{l}197 \\
140\end{array}$ & 265 & 217 \\
\hline $8-50$ & 20.0 & 0.01429 & 70 & 62 & 66 \\
\hline $40-80$ & 56.7 & 0.0404 & 25 & 11 & 18 \\
\hline & & & & $10.5 *$ & 10.5 \\
\hline
\end{tabular}

* Machinery, NYC to LAA 
economics of freight pipelines will be addressed in section 6.0 below. First, however, there are two additional aspects of the scenario to be discussed.

\subsection{Freight-Passenger Interaction.}

The foregoing discussion has treated only freight transportation modes because the subject of the present study is pipelines. And while it is clearly reasonable to postulate the future existence of freight pipelines and to examine their economics, energetics, and technology, passenger pipelines appear to be too far in the future to merit present study. However, the earlier discussion of other modes makes mandatory some comment on passenger transportation.

A most significant and attractive aspect of the scenario described earlier is the fact that the type of freight trains which were postulated, i.e., small and fast, are compatible with a true high-speed passenger service. Thus, a part of the scenario is the capture of significant portions of the shorthaul air passenger market. While it seems unlikely that the trunk airlines would lose much business on the longer trips, say 500 miles and greater, there is every reason to believe that large portions of the short-haul passenger business could be assumed by the rails. And that is precisely the portion of the air transport market that is energy-inefficient, uneconomic, and generally subsidized. As noted earlier, while the details of how the many classes of cargo might fare under the scenario are beyond the present study, it seems clear that the economics of fast trains would receive very considerable support from their compatibility with fast passenger service.

\subsection{Compatibility with Projected Trends}

While it has been stated earlier that detailed consideration will not be given to types of freight in this study, 
an observation can be made regarding trends as between the two major categories: bulk commodities and manufactures. Morton [1974] points out that "the economic consumption of bulk commodities has not kept pace with the growth of GNP." He also discusses traffic in manufactures, i.e., manufactured goods:

"The other major category of freight traffic - manufactures consists primarily of finished goods or parts moving from factory to assembly plant, warehouse, or retail outlet. Manufactures typically move in packages or discrete units; shipments tend to be of lower volume than bulk commodity flows, smaller, and less regular. The goods themselves tend to be of lower density (i.e., lighter) and of higher value per unit of weight. They are frequently fragile or perishable and subject to loss of market value as a function of time. Traffic in manufactures constitutes the bulk of truck cargo. Although the railroads have already lost much traffic in manufactures to trucking, this traffic still accounts for 25-40\% of railroad ton-miles (depending on definition) and a still larger proportion, it is thought, or revenues and profits. It is important, therefore, to understand how the demand for the transport of manufactures has been changing.

"Whereas the weight of manufactured goods must bear some reasonably constant relation to the weight of raw material inputs, it is apparent that traffic in manufactures is also growing more slowly when measured in weight units than in real GNP. Aggregate intercity freight tonnage in bulk commodities and manufactures combined has been growing only about $60 \%$ as fast as real GNP during the postwar period, Traffic in manufactures is growing faster than bulk commodity traffic, however, particularly when measured in terms of freight revenues. The primary causes of this relatively faster growth of traffic in manufactures are an increase in number of shipments and in the quality of freight service demanded. As per capita incomes rise, there is 
a shift in consumer expenditures toward more highly fabricated products. To produce these, commodities must often pass through more stages of fabrication. Increasing specialization or "division of labor" in manufacturing industry also contributes to a rising number of interplant shipments. Hence, the total tonnage of manufactured goods shipped tends to rise more rapidly than bulk-commodity tonnage. The proliferation of distinct brands, models, and styles of manufactures tends to reduce the size of individual shipments and to require a more elaborate system of distribution. All these effects tend to increase the number of shipments of manufactured goods.

"Another fundamental change in the freight market is the higher standards of freight service that shippers of manufactures are demanding. The shift toward higher standards of freight service parallels a shift in most markets toward higher quality products and services. As the economy evolves toward production of more highly fabricated goods and more expensive brands, models, and styles, the value of manufactures per unit of weight tends to rise because of the relatively greater inputs of labor and capital. As the amount and cost of working capital tied up in goods rise, there is a tendency to opt for speedier, more reliable deliveries as a way of controliing this carrying cost. Growing sophistication among shippers concerning the tradeoffs between transport and other components of the total distribution bill (e.g., inventory) is also partially responsible for the gradual shift to higher-quality freight service.

"Highly fabricated and expensive goods are inclined to be fragile, perishable, or otherwise damage-prone, prompting the use of premium transport service. The reliability, speed, and convenience of deliveries is part of the product quality or service that the buyer looks for. This has been a powerful force in causing shippers to shift toward higher standards of freight service, so that freight demand has become more service-elastic and less price-elastic. The monetary value to shippers of swift, 
reliable delivery may be rather surprising. In Great Britain, for example, trucking firms have begun to specialize in offering guaranteed delivery. Freight rates for guaranteed second-day delivery are roughly $40 \%$ greater than for seventh-day delivery, and rates for overnight delivery are about twice as high as for second-day delivery."

The general picture, then, is of a stagnating market in bulk commodity transport, and a growing market in transport of manufactures, a large part of which are highly fabricated and expensive goods, for which the value of time, i.e., speed, tends to be high. This is precisely the kind of market situation that the unconventional scenario described above would best capitalize upon. Thus, while quantitative analysis has not been adduced to confirm the validity of the scenario, it can be said that qualitative analysis of trends shows it to be consistent with observed patterns of market evolution. 


\subsection{FREIGHT PIPELINES}

This section includes a report and analysis of the papers presented and discussions held during the International Symposium on Freight Pipelines, held December 5-8, 1976, in Washington, D.C. There was excellent coverage of the subject. Unfortunately, proceedings were not published, so that the present discussion is largely a reconstruction from the recollections and notes of the author.

\subsection{History of Freight Pipelines}

A recapitulation of freight pipeline history generally begins by taking note of pneumatic mail tubes. Such systems began operation in England in 1940. [Baker 76], in Germany in 1965 [Brauer 76], in France in 1967 [zandi 74], and in the United States in 1892 [Zandi 74]. However, these tubes were not true freight systems, but communication systems. They do not qualify as freight systems in the sense of carrying significant amounts of payload at reasonable ratios of cargo-to vehicle weight.

The only true freight pipelines now operating on a commercial scale are slurry lines. Such systems have been extensively studied in many countries [Gandhi 76], and numerous ones have been built. Of the papers presented during the symposium mentioned above, almost a dozen reported on projects ranging from conceptual studies and experimental facilities through pilot plants to operating commercial systems. Table 6.1-1 lists the systems known to have been in operation by 1975 [Gray 75].

The experience with slurry lines has not been universally encouraging. Table 6.1-2 lists a dozen Canadian projects that were never built [Jensen 76]. All except number 12 were to have been slurry lines.

The development of other types of freight pipelines than slurry lines has been much slower. The only one reported to be in commercial operation is in Rusisia [New Scientist 75, 
TABLE 6.1-1

Slurry pipelines in operation by 1975

\begin{tabular}{|c|c|c|c|c|c|}
\hline Slurry material & Location & $\begin{array}{l}\text { ength } \\
\text { (mi) }\end{array}$ & $\begin{array}{l}\text { Diam. } \\
\text { (in) }\end{array}$ & $\begin{array}{l}\text { Annual } \\
\text { Thruput } \\
\text { (millions } \\
\text { tons/yr) } \\
\end{array}$ & $\begin{array}{l}\text { Init. } \\
\text { Op'n. }\end{array}$ \\
\hline Coal & $\begin{array}{l}\text { Consolidation } \\
\text { Black Mesa }\end{array}$ & $\begin{array}{l}108 \\
273\end{array}$ & $\begin{array}{l}10 . \\
18\end{array}$ & $\therefore 1.3$ & 1957 \\
\hline Limestone & $\begin{array}{l}\text { Calaveras } \\
\text { Rugby } \\
\text { Trinidad } \\
\text { Colombia }\end{array}$ & $\begin{array}{r}17 \\
57 \\
6 \\
17\end{array}$ & $\begin{array}{r}7 \\
10 \\
8 \\
7\end{array}$ & $\begin{array}{l}1.5 \\
1.7 \\
0.6 \\
0.4\end{array}$ & $\begin{array}{l}1971 \\
1964 \\
1959 \\
1944\end{array}$ \\
\hline $\begin{array}{l}\text { Copper concen- } \\
\text { trate }\end{array}$ & $\begin{array}{l}\text { Bougainville } \\
\text { West Irian } \\
\text { KBI Turkey } \\
\text { Pinto Valley }\end{array}$ & $\begin{array}{l}17 \\
69 \\
38 \\
11\end{array}$ & $\begin{array}{l}6 \\
4 \\
5 \\
4\end{array}$ & $\begin{array}{l}1.0 \\
0.3 \\
1.0 \\
0.4\end{array}$ & $\begin{array}{l}1972 \\
1972 \\
- \\
1974\end{array}$ \\
\hline $\begin{array}{l}\text { Magnetite } \\
\text { concentrate }\end{array}$ & $\begin{array}{l}\text { Tasmania } \\
\text { Waipipi (land) } \\
\text { Waipipi (offshore) }\end{array}$ & $\begin{array}{l}53 \\
4 \\
1.8\end{array}$ & $\begin{array}{r}9 \\
8 \\
12\end{array}$ & $\begin{array}{l}2 \cdot 3 \\
1 \cdot 0 \\
1 \cdot 0\end{array}$ & $\begin{array}{l}1967 \\
1971 \\
1971\end{array}$ \\
\hline $\begin{array}{l}\text { Magnetite and } \\
\text { hematite }\end{array}$ & Pena Colorado & 30 & 8 & 1.8 & 1974 \\
\hline Gilsonite & $\begin{array}{l}\text { American } \\
\text { gilsonite }\end{array}$ & 72 & 6 & 0.4 & 1957 \\
\hline Tails & Japan & 44 & 12 & $0 . \epsilon$ & 1968 \\
\hline $\begin{array}{l}\text { Nickel refin- } \\
\text { ery tailings }\end{array}$ & $\begin{array}{l}\text { Western } \\
\text { mining }\end{array}$ & $4 \cdot 3$ & 4 & $0 . i$ & 1970 \\
\hline Phosphate pulp & Florida & 5 & 14 & 1.0 & 1949 \\
\hline Kaolin & Georgia & 10 & - & - & 1950 \\
\hline
\end{tabular}

Sources: Gray 75, Zandi 74 . 
TABLE $6.1-2$

CANADIAN LONG DISIAIJCE SOLIO PIPELINES PROPOSED BUI MEVER BUILI

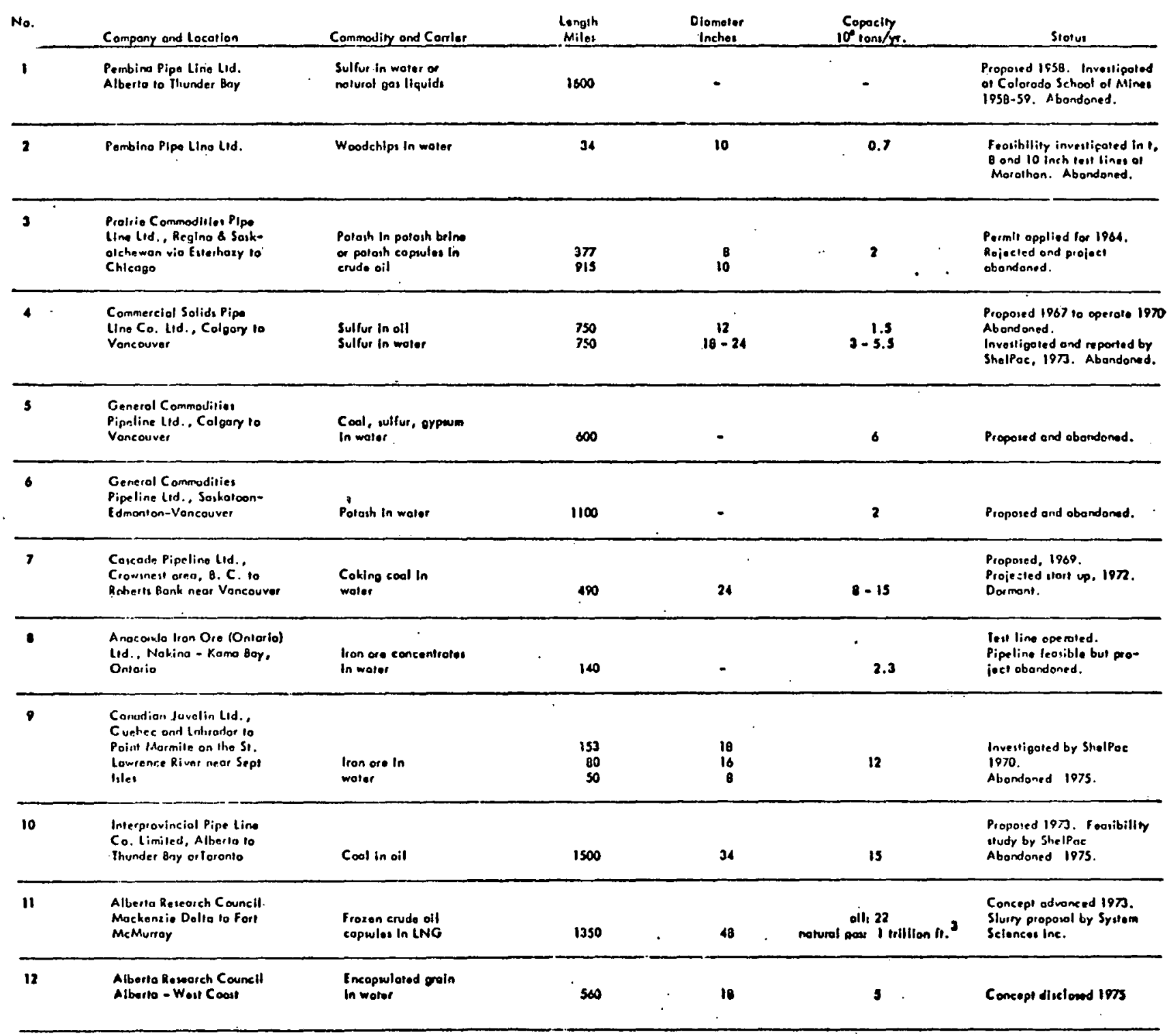


Jvarsheistivili 76], and is said to be $2.2 \mathrm{~km}$ long, $1 \mathrm{~m}$ in diameter, and to carry sand and gravel. The soviets are also reported to be testing a line $80 \mathrm{~km}$ long, north of Moscow, which carries ore in trains of six capsules, by pneumatic propulsion. other projects are in progress.

In the United States, Tubexpress Systems, Inc., of Houston is offering pneumatic capsule pipeline systems to the commercial market [Carstens 76a, Tubexpress 76, Carstens 76b], although at this writing (October 1977) firm orders have not been received. Tubexpress has a large test facility in Houston. which includes a complete, full-size test loop.

\subsection{System Development Requirements}

In describing the unconventional scenario of the preceding section, it was noted that the rail projection which was postulated did not appear to involve any significant development of new technology. On the other hand, the projection of freight pipelines other than slurries postulates a significant amount of development. At the same time, however, it is recognized that the technologies of the largest and most expensive portions of the freight pipeline system already exist. Laying pipe up to five feet in diameter and building associated compression or pumping stations, even in extremely difficult environments, are established commercial technology. And those are the most expensive and time-consuming parts of the system. On the other hand, numerous functions and techniques never before demonstrated must be perfected before the freight pipelines postulated in the scenario can become reality. Before discussing these development areas, it is well to first identify some performance requirements for the system. Having identified these requirements, it will then be possible to define the research, development and demonstration necessary to bring the concepts to fruition. 


\subsubsection{Types of freight and freight pipelines}

In Section 5.7 above, the distinction in types of freight between bulk commodities and manufactures was recognized. The unconventional scenario developed in the preceding section envisioned that a substantial amount of normally slow moving, bulk commodity traffic, e.g., coal, ore, etc., would be absorbed by freight pipelines, leaving the railroads free to upgrade their facilities, increase speed of service, and generally to serve the higher speed market. It is therefore necessary to first examine freight pipelines which haul bulk commodities.

This is precisely what the slurry pipelines do. However, liquid slurrying is only practical where:

1) there is adequate supply of water available,

2) separation of the water from the commodity is easy, or a market for the water exists, and

3) the commodity is unaffected by wetting and drying.

Moving certain bulk commodities in pneumatic slurries does not require the special conditions enumerated above. However, gas compression is a very energy-consuming process, which is one of the reasons that led Duckworth [76] to conclude that pneumatic pipelines are "essentially inhouse systems," i.e., not suitable for long distance. There may be exceptions, e.g., the pneumatic slurrying of coal in its own gas [Nichols 76]. Nevertheless, if common-carrier pipelining of freight is ever to capture a significant portion of the market, it most likely will utilize capsule pipelines. Only capsules can provide the flexibility to make the special conditions identified above unnecessary. Any one of these conditions would severely restrict market penetration of the freight pipeline.

Several types of capsule pipelines can be envisioned. The Tubexpress system discussed earlier is known as a pneumatic capsule system, $i . e .$, the capsules are propelled through the 
pipe by compressed air, which is also reported to be the propulsion means for the Russian systems. The capsules are supported on wheels. In principle, they could be supported on an air cushion but at a greater consumption of energy and the practical difficulties of obtaining initial levitation.

The capsules would also be propelled and/or supported by a liquid, in which case they are referred to as hydraulic capsule systems. A hydraulic capsule concept which would be powered by electromagnetic action upon the capsule body, similar to that of a linear induction motor, has been studied by Liu and his colleagues at the University of Missouri at Columbia [Liu 76a, 76b, 77a, 77b]. The pump concept appears attractive and deserving of further study and experiment. However, need for the water is not clear since it only serves to levitate the capsule and lubricate its passage through the pipe, functions which wheels or rollers such as those used in the pneumatic capsule systems could also perform.

In principle, capsule pipelines could be constructed to operate without fluid action if the capsules were supported on wheels, rollers or magnetic fields and were continuously powered by electric rails, for example, so that accelerative and decelerative power were continuously available.

From this brief discussion, the reader can readily visualize some of the problems, such as propulsion, braking, and switching, facing the designer of a capsule pipeline. From a review of the references mentioned above, and of other available literature, it is the tentative conclusion of this study that the most immediately realizable system is the pneumatic capsule pipeline.

\subsubsection{Economic Feasibility of Freight Pipelines}

Thus far, the inferences have been that if the railroads could be induced to expand into the high-speed, high- value cargo field, an over-all transportation energy saving 
could be realized. At the same time, an opportunity would be created for freight pipelines to assume some of the heavy, slow bulk commodity transportation. It was also concluded that to serve this role most effectively, the pipeline should be a capsule system, as opposed to a slurry system, so that it would possess wide cargo flexibility. For an order of magnitude examination of the economics of such a system, a cost model was developed.

Natural gas pipelines were selected as the prototype because they more nearly resemble the pneumatic capsule system than do the oil lines. Construction costs reported by the FPC for the 10-year period 1968-77 (government fiscal years) were reviewed and a regression analysis was performed on the larger sizes, $i: e .$, 20-inch nominal diameter and greater, to obtain the functional relationship of cost to line diameter.

This model still requires an adjustment to incorporate the cost of the second pipe. That is, the freight pipeline system of the type that has been discussed above would be moving freight in both directions, and thus would require two pipes instead of the usual one. To include this feature in the cost model, the breakdowns of investment among system components, i.e., Row cost, pipe and fittings, pumping equipment, etc., for ten pipeline companies were analyzed. Those cost elements which are doubled or otherwise increased by the construction of the second line were segregated, and that portion of the cost was increased according to the seven-tenths power law which is commonly used for estimating the effect of scale on plant construction.

Next, the actual cost of a large gas pipeline, i.e., 42-indiameter and greater than 1000-mile length, which was completed in 1975, was reviewed. That cost was first escalated to 1977 , using the Oil and Gas Journal pipeline construction cost index. Then, using that baseline estimate and the cost model described above, the cost of a two-way, 48-in freight pipeline was estimated. The result was an estimate of $\$ 2.08 \mathrm{~m} 11 \mathrm{lion}$ per mile. 
Independent of the effort just described, discussions were held with Tubexpress Systems, Inc., of Houston, a subsidiary of Transco. Tubexpress agreed to cooperate, and accordingly conducted a number of computer runs on their cost model for the Tubexpress system. This is the same model which they use in preparing their commercial quotations, and is naturally much more detailed and specific than the cost model developed under this study and described above. For the 48-in line, their construction cost estimate was $\$ 1.85 \mathrm{million} / \mathrm{mile}$. for a $500-\mathrm{mile}$ length. Interestingly, the cost was found not to be highly sensitive to length.

These results were then applied to the pipeline economic model (PEM) developed earlier in this project and described in Reports $R-3021$ and R-3069, to determine what throughput would be required to achieve economic viability if the average tariffs projected in section 5.4 above could be realized. It was concluded that the system would require a throughput exceeding 10 million tons/year. At what appear to be reasonable capsule speeds and separations, as indicated by Marstens, this throughput is consistent with utilization factors as low as $30 \%$.

While this analysis is much too preliminary to justify any broad conclusions, it does seem clear that the concept merits further study. Such study is therefore strongly recommended. 
REFERENCES

AGA publication [1976], "The Gas Industry - Its Energy Supply Problems and their Solutions," American Gas Association, 1515 Wilson Boulevard, Arlington, Virginia, 22209, July 1976.

Baker, P. J. [1976], "U. K. Experience in Solids Pipeline," British Hydromechanic Research Association, Cranfield, Bedford, England, 1976.

Baker, P. J., J. A. Bunce [1.976], "The U. K. Pneumo-Capsule Pipeline Test Facility," British Hydromechanics Research Association, Transport \& Road Research Laboratory, Cranfield, Bedford, England, 1976.

Bekker, M. G. [1956], "Theory of Land Locomotion - The Mechanics of Vehicle Mobility," The University of Michigan Press, 1956.

Bennett, C. P. [1976], "Wooden Pipeline," Department of Mechanical Engineering, The University of Manitoba, Winnipeg, Manitoba, Canada, 1976.

Bowen, W. J. (Jack) [1977], "Gas-pipeline Future Tied to Supply," Petroleum/2000, pp. 312-316, August 1977.

Brauer, H. [1976], "Freight Pipeline in Germany," Technische Universitat, Berline, Germany, 1976.

Cannon, R. E., C. B. Sutton [1977], "Four Eras Highlight Gas Processing History," Petroleum/2000, August 1977.

Carameros, George D. Jr. [1977], "LNG to Play Role in the Naturalgas Industry's Future," Petroleum/2000, August 1977.

Carstens, M. R. [1976a], "The Potential of Pneumatic Capsule Pipeline," School of Civil Engineering, Georgia Institute of Technology, Atlanta, Georgia, 1976.

Carstens, M. R., D. W. Leva [1976b], "Design of a Capsule Pipeline," Tubexpress Systems Inc., presented at the Joint Petroleum Mechanical Engineering and Pressure Vessels and Piping Conference, Mexico City, Mexico, September 19-24, 1976.

Dosher, John R. [1977], "U. S. Refining Industry Faces Political, Economic Hurdles," Petroleum/2000, August 1977. 
Duckworth, R. A. [1976], "Pneumatic Pipeline," Department of Mechanical Engineering, The City University, London, England, 1976.

Federal Energy Administration [1974], "Project Independence," Project Independence Blueprint Final of the Task Force Report, Volume 2, November 1974.

Gabrielli, G., Th. von Karman [1950], "What Frice speed? Specific Power Required for Propulsion of Vehicles," Mechanical Engineering, pp. 775-781, October 1950.

Gandhi, R. L., M. D. Weston[1976], "Status of Slurry Pipeline in the Americas," San Francisco, California, 1976.

Gibeaut, William [1976], American Gas Association, Arlington, Virginia, letter to ERDA, October 1976.

Granville, Maurice F., A LOOK AT THE FUTURE," The Role of Petroleum to the Year 2000," Petroleum/2000, pp. 57.

Granville, Maurice F. [1977], "Petroleum's Role from now to the end of the century," Petroleum/2000, August 1977.

Gray, W. S., P. F. Mason [1975], "Slurry Pipelines: What the Coal Man Should know in the Planning stage," Coal Age, pp. 58-62, August 1975 .

Hopkins, John B. [1975], "Railroads and the Environment Estimation of Fuel Consumption in Rail Transportation," Volume 1 - Analytical Model, October 1975.

Hopkins, John B. [1976], "Recent Measurements of Fuel Consumption in Rail Freight Service," Proceedings of the Third National Conference on Effects of Energy Constraints on Transportation Systems, August 1976.

Jensen, E. J. [1976], "Hydro-Capsule Pipeline - A Canadian Experience," Engineering Division, Alberta Research Council, Edmonton, Alberta, Canada, 1976.

Jones, Vernon T. [1977], "Product Pipelines - Today and Tomorrow," Petroleum/2000, pp. 316-318, August 1977.

Jvarsheistivili, A. G. [1976], "Freight Pipeline - A Russian Experience, Institute of Mining Mechanics at the Academy of Sciences of Georgia, Tbilis, Georgia, U.S.S.R., 1976. 
Kawashima, T. [1976], "Freight Pipeline in Japan," Department of Mining and Mineral Engineering, Tohoku University, Sendai, Japan, 1976.

Lawrence, George H., A LOOK AT THE FUTURE, "The Role of Gas to the Year 2000," Petroleum/2000; pp. 71.

Lawrence, George H. [1977], "Gas Industry Outlook Good for 2000 ," Petroleum/2000, August 1977.

Leilich, Robert H. [1976]; "Energy and Economic Impacts of Projected Freight Transportation Improvements," Proceedings of the Third National Conference on Effects of Energy Constraints on Transportation Systems, August 1976.

Leilich, R. H., R. D. Cohen, A. Gezen, M. J. Kendrick [1976], "Energy and Economic Impacts of Projected Freight Transportation Improvements," November 1976.

Iiu, Henry, Donald I. Gibson [1976], "Hydraulic Container Pipelining - A Future Transportation System to Conserve Energy," University of Missouri, presented at UMR-MEC Conference on Energy, October 12, 1976.

Liu, H., J. Rathke [1976], "Electromagnetic Capsule Pumps;" University of Missouri, Columbia, Missouri, 1976.

Liu, Henry [1977], "The Fluid Mechanics of Capsule Pipelining," University of Missouri, presented at the 2nd specialty Conference of the Engineering Mechanics Division, American Society of Civil Engineers, Raleigh, North Carolina, May 23-25, 1977 .

Liu, Henry, Donald L, Gibson [1977], "Conserving Energy and Protecting Environment by Using Freight Pipelines -A Technology Assessment," University of Missouri, presented at the 4 th Annual UMR-MEC Conference on Energy, October $11,12, \& 13,1977$.

Malhotra, R. C. [1976], "An Indian Experience - Pilot Plant Study for the Hydraulic Transportation of Bauxite ore," Department of Applied Mechanics, Indian Institute of Technology, Hauz Khas, New Delhi, India, 1976.

Mathias, C. P., B. L. Kline, J. E. Moody [1977], "Gas Processing Looks to the Future," Petroleum/2000, August 1977.

Mihelich, J. I. [1977], "Controlled Rolled Steels for Offshore Pipeline," Journal of Petroleum Technology, June 1977. 
Miller, Michael P. [1976a], "Energy Efficiency of Current Intercity Passenger Transportation Modes," Proceedings of the Third National Conference on Effects of Energy Constraints on Transportation Systems, August 1976.

Miller, Michael P. [1976b], "Intercity Freight Fuel Utilization at Low Package Densities - Airplanes, Express Trains and Trucks -," Proceedings of the Third National Conference on Effects of Energy Constraints on Transportation Systems, August 1977 .

Mooz, W. E. [1971], "The Effect of Fuel Price Increases on Energy Intensiveness of Freight Transport," prepared under a Grant from National science Foundation, December 1971.

Morton, Alexander Lyall [1974], "The Changing Market for Rail Freight Transport," Harvard University, 1974.

Nichols, D. G., B. S. Patel, C. Iin, K. C. Chaung, and C. Y. Win [1976], "An Analysis of the Pneumatic Pipeline Transmission of Coal with Fuel Gas," Department of Chemical Engineering, West Virginia University, Morgantown, West Virginia, 1976.

O'Donnell, John P. [1977], "Pipelines Continue to Play Major Role," Petroleum/2000, August 1977.

Richardson, Elliot I., Secretary, U. S. Department of Commerce, Robert I. Hagan, Acting Director, Bureau of the Census [1976], Statistical Abstract of the United States, 97 th Annual Edition.

Sanders, William M. [1977], "Arctic Lines - Today and Tomorrow," Petroleum/2000, August 1977.

Shonka, D. B., A. S. Loebl, N. S. Malthouse, "Transportation Energy Conservation Data Book: Supplement 1," Oak Ridge National Laboratory report ORNL - 5232 .

Shure, Lloyd I., John T. Milton, James O. Spriggs [1973], "Energy Uses in Transportation - What Does the Future Hold?" West Coast Meeting, Portland, Oregon, August 20-23, 1973 .

Singer, Sidney C. Jr. [1975], "Handbook of Engineering Fundamentals (Eshbach and Souders, ed.), Wiley \& Sons, New York, 1975.

Talbot, William J. Jr., Ben B. Creel [1977], "Future to see 6,000-ft.-deep Lines," Petroleum/2000, August 1977. 
Taylor, John W. R. [1968-69], "Jane's All the World's Aircraft," Sampson Low, Marston \& Co., Ltd., P. O. Box No. 2I.G., St. Giles House, 49150 Poland Street, London, W. I., England, 1968-69.

Tihansky, Dennis P. [1972], "Methods for Estimating the Volume and Energy Demand of Freight Transport," prepared for the National Science Foundation, December 1972.

Transportation Association of America [1976], "Transportation Facts \& Trends," Twelfth Edition -- 1975, published July 1976.

Tubexpress Systems Inc. publication [1976], "Pipeline Transportation for Solid Cargo," Tubexpress system Inc., P. O. Box 1396, Houston, Texas, 77001, 1976.

Wacker, John Jr. [1977], "Crude-oil Pipeline Expansion Foreseen," Petroleum/2000, pp. 289-291, August 1977.

Wagner, Michael J. [1977], "Pipeline Builders Solving New Problems," Petroleum/2000, August 1977.

Warner, Rawleigh Jr. [1977], "Petroleum Faces Transition Period," Petroleum/2000. August 1977.

Wett, Ted [1977], "Coal: Future Source of Oil and Gas," Petroleum/2000, pp. 517-520, August 1977.

* Petroleum/2000, special issue of the Oil and Gas Journal, Petroleum Publishing Company, August 1977. 